\title{
1 Iron mineral structure, reactivity, and isotopic composition 2 in a South Pacific Gyre ferromanganese nodule over $4 \mathrm{Ma}$
}

$4 \quad$ Matthew A. Marcus ${ }^{1 *}$, Katrina J. Edwards ${ }^{2 \dagger}$, Bleuenn Gueguen ${ }^{3,4,5}$, Sirine C. Fakra ${ }^{1}$, Gregory Horn $^{2}$, Nicolas A. Jelinski ${ }^{6}$, Olivier Rouxel ${ }^{3}$, Jeffry Sorensen ${ }^{6}$, Brandy M. Toner ${ }^{6}$

$8{ }^{1}$ Advanced Light Source, Lawrence Berkeley National Laboratory, Berkeley CA 94720, USA

$9 \quad{ }^{2}$ Department of Biological Sciences, University of Southern California, Los Angeles, CA, USA

$10 \quad(\dot{\dagger}$ deceased)

$11{ }^{3}$ IFREMER, Centre de Brest, Unité Géosciences Marines, 29280 Plouzané, France

$12{ }^{4}$ Institut Universitaire Européen de la Mer, UMR 6538, Université de Brest, BP 80 F- 29280

13 Plouzané, France

$14{ }^{5}$ Department of Geology and Geophysics, Yale University, New Haven, CT, USA 06511

$15{ }^{6}$ Department of Soil, Water, and Climate, University of Minnesota, St. Paul, MN, USA 55108

18 *Corresponding author, mamarcus@lbl.gov, ph: 510-495-2106, fax: 510-486-4102.

19

20 Submitted to: Geochimica et Cosmochimica Acta 
Abstract -

Deep-sea ferromanganese nodules accumulate trace elements from seawater and underlying sediment porewaters during the growth of concentric mineral layers over millions of years. These trace elements have the potential to record past ocean geochemical conditions. The goal of this study was to determine whether Fe mineral alteration occurs and how the speciation of trace elements responds to alteration over $\sim 3.7 \mathrm{Ma}$ of marine ferromanganese nodule (MFN) formation, a timeline constrained by estimates from ${ }^{9} \mathrm{Be} /{ }^{10} \mathrm{Be}$ concentrations in the nodule material. We determined Fe-bearing phases and Fe isotope composition in a South Pacific Gyre (SPG) nodule. Specifically, the distribution patterns and speciation of trace element uptake by these Fe phases were investigated. The time interval covered by the growth of our sample of the nodule was derived from ${ }^{9} \mathrm{Be} /{ }^{10} \mathrm{Be}$ accelerator mass spectrometry (AMS). The composition and distribution of major and trace elements were mapped at various spatial scales, using micro-X-ray fluorescence $(\mu \mathrm{XRF})$, electron microprobe analysis (EMPA), and inductively coupled plasma mass spectrometry (ICP-MS). Fe phases were characterized by micro-extended X-ray absorption fine structure ( $\mu$ EXAFS) spectroscopy and micro-X-ray diffraction ( $\mu$ XRD). Speciation of Ti and $\mathrm{V}$, associated with Fe, was measured using micro-X-ray absorption near edge structure ( $\mu$ XANES) spectroscopy. Iron isotope composition $\left(\delta^{56 / 54} \mathrm{Fe}\right)$ in subsamples of $1-3 \mathrm{~mm}$ increments along the radius of the nodule was determined with multiple-collector ICP-MS (MCICP-MS). The SPG nodule formed through primarily hydrogeneous inputs at a rate of $4.0 \pm 0.4$ $\mathrm{mm} / \mathrm{Ma}$. The nodule exhibited a high diversity of Fe mineral phases: feroxyhite $(\delta-\mathrm{FeOOH})$, goethite $(\alpha-\mathrm{FeOOH})$, lepidocrocite $(\gamma-\mathrm{FeOOH})$, and poorly ordered ferrihydrite-like phases.

These findings provide evidence that $\mathrm{Fe}$ oxyhydroxides within the nodule undergo alteration to more stable phases over millions of years. Trace Ti and V were spatially correlated with Fe and found to be adsorbed to Fe-bearing minerals. Ti/Fe and V/Fe ratios, and $\mathrm{Ti}$ and $\mathrm{V}$ speciation, did not vary along the nodule radius. The $\delta^{56 / 54} \mathrm{Fe}$ values, when averaged over sample increments representing 0.25 to $0.75 \mathrm{Ma}$, were homogeneous within uncertainty along the nodule radius, at $0.12 \pm 0.07 \%$ o ( $2 \mathrm{sd}, \mathrm{n}=10)$. Our results indicate that the Fe isotope composition of the nodule remained constant during nodule growth and that mineral alteration did not affect the primary $\mathrm{Fe}$ isotope composition of the nodule. Furthermore, the average $\delta^{56 / 54} \mathrm{Fe}$ value of $-0.12 \%$ we find is consistent with Fe sourced from continental eolian particles (dust). Despite mineral alteration,

54 the trace element partitioning of $\mathrm{Ti}$ and $\mathrm{V}$, and $\mathrm{Fe}$ isotope composition, do not appear to change

55 within the sensitivity of our measurements. These findings suggest that Fe oxyhydroxides within

56 hydrogenetic ferromanganese nodules are out of geochemical contact with seawater once they are 
covered by subsequent concentric mineral layers. Even though Fe-bearing minerals are altered, trace element ratios, speciation and $\mathrm{Fe}$ isotope composition are preserved within the nodule.

\section{INTRODUCTION}

Marine ferromanganese nodules (MFN) have attracted interest for many decades due to their economic potential and their possible use as recorders of the marine geochemical environment over millions of years (Calvert and Cronan, 1978; Koschinsky and Hein, 2003). These nodules are among the slowest-growing natural materials known, with growth rates measured in $\mathrm{mm} / \mathrm{Ma}$, and characterized by alternating layers of Mn-rich and Fe-rich phases precipitated around a nucleus (e.g. shark tooth, rock debris) (Banerjee et al., 1999; de Lange et al., 1992). MFNs occur on the seafloor in water depths $>4000 \mathrm{~m}$, usually below the calcite compensation depth and in well oxygenated environments. They generally form in inactive tectonic settings where very slow rates of sedimentation $(<10 \mathrm{~cm} / 1000 \mathrm{yrs})$ protect metals from dilution with background sediments. The abyssal plains, such as the Clarion/Clipperton zone in the Central Pacific Ocean have the most abundant nodule fields at the seafloor (Hein et al., 2013). MFNs are different from ferromanganese crusts that are deposited in shallower environments mostly on the flanks of seamounts by hydrogenous precipitation from dissolved trace metals in seawater. The sources of metals to MFNs can include: (1) a hydrogenetic source, (2) a diagenetic source, largely derived from the decay of organic matter, and (3) a hydrothermal source. The diagenetic source is generally considered predominant, indicating the important role of organic matter decay during early diagenesis processes in oxic sediments that release dissolved trace metals to sediment porewaters (Heggie et al., 1986; Klinkhammer et al., 1982; Morford and Emerson, 1999; Sawlan and Murray, 1983). However, hydrogenetic nodules do form under lowproductivity waters. In addition, microorganisms have been proposed as geochemical agents in Mn- and Fe-cycling in sediments leading to the formation of MFN (Wang et al., 2009), whereas sorption experiments of $\mathrm{Ni}$ on ferrihydrite showed that the presence of organic material decreased the sorption efficiency of Ni on the mineral (Eickhoff et al., 2014) Iron is often the most or second-most abundant metal in MFNs, and is present as Febearing mineral phases known to be chemically reactive with trace elements. For instance, rare earth elements in MFN are thought to be hosted by the Fe-phases (Elderfield et al., 1981).

89 times over the past decades (Aplin and Cronan, 1985; Banakar and Tarkian, 1991; Cronan, 1975;

90 Dymond et al., 1984; Elderfield et al., 1981; Martin-Barajas et al., 1991; Verlaan et al., 2004; 
91 Yoshikawa, 1991), there has been comparatively little research on Fe mineral phases. This is

92 likely due to analytical difficulties associated with distinguishing among the suite of Fe

93 oxyhydroxide phases that may occur, as well as the fine spatial scale over which mineralogy

94 varies in nodules. The use of traditional techniques such as powder X-ray diffraction (XRD) and

$95 \quad{ }^{57} \mathrm{Fe}$ Mossbauer spectroscopy has been largely unsuccessful due to the poorly crystalline,

96 distorted structures, and intergrowth with Mn oxides (Murad and Schwertmann, 1988). Further,

97 most of the literature on MFN mineralogy is unreliable; for example, it was once typical to

98 identify a Mn-rich phase as "todokorite" based on optical microscopy and perhaps a bulk XRD

99 pattern. Synchrotron X-ray microprobe ( $\mu$ XRF, $\mu$ XAS and $\mu$ XRD) techniques allow us to tackle

100 these issues on unprocessed samples (Manceau et al., 2002). To date, this approach has been

101 used infrequently, but successfully, to study the incorporation of trace elements in nodule

102 nanophase oxides and using marine ferromanganese deposits as natural long-term sorption

103 laboratories (Manceau et al., 2014; Marcus et al., 2004b; Takahashi et al., 2007; Takahashi et al.,

104 2000).

105 Despite the analytical challenges, the structure and reactivity of Fe minerals in MFNs

106 must be defined if we wish to validate them as recorders of past marine conditions. Specifically,

107 mineral transformation processes may result in a blurring or over-writing of trace element

108 speciation and isotopic signatures. For example, it is known that trace metal associations (e.g. Ni,

$109 \mathrm{Zn}$ ) with $\mathrm{Fe}$ minerals (e.g. goethite) can change in the presence of $\mathrm{Fe}^{2+}$ under laboratory

110 conditions, especially under advective flow conditions (Frierdich and Catalano, 2012; Frierdich et

111 al., 2011). Ferrihydrite in particular has been shown to incorporate additional $\mathrm{Cu}$ and $\mathrm{Zn}$ during

$112 \mathrm{Fe}^{2+}$ catalyzed recrystallization, as reviewed by Latta et al. (2012). From a Mn mineral

113 perspective, it has been demonstrated in laboratory studies that Ni uptake by the Mn oxide

114 birnessite is $\mathrm{pH}$ dependent, but also reversible, calling into question its use as a paleo-pH

115 indicator (Peacock, 2009). However, transition metals such as Ni, Mn, and Co have been shown

116 to slow the rate of recrystallization of poorly ordered Fe oxyhydroxides (Cornell et al., 1992);

117 which could result in preservation of the original chemical association between the mineral and

118 trace element. Perhaps the primary factor in preservation of trace element signatures is the degree

119 to which buried mineral layers are in geochemical contact with younger deposits and current

120 seawater conditions. If recrystallization creates $\mathrm{Fe}$ mineral phases with similar reactive properties

121 and the mineral is out of contact with seawater, then we might expect the preservation of trace

122 element signatures over time in nodules.

123 In the present contribution, we use a variety of spectroscopic and isotopic approaches to

124 address whether Fe minerals transform to stable phases in a South Pacific Gyre over time. In 
addition, we ask whether Fe minerals can retain the geochemical signatures of associated trace elements and faithfully record the Fe isotope composition of seawater through time.

\section{Nodule description and methods}

\section{$2.1 \quad$ Description of the sample}

\subsubsection{Sample collection and handling}

The nodule was collected December 24, 2006 (D'Hondt et al., 2009), at 2603.09'S, $156^{\circ} 53.65^{\prime} \mathrm{W}$, at $5126 \mathrm{~m}$ water depth during the Knox02RR cruise of the RV Roger Revelle, using a multicore sampler. The site, South Pacific Gyre-2 (SPG-2), is characterized as follows: SPG-2 is located in a region of abyssal hill topography trending roughly NE-SW $\left(065^{\circ}\right)$. Two populations of abyssal hill topography are present. The larger hills have relief ranging from 300$400 \mathrm{~m}$ with a spacing of $\sim 20 \mathrm{~km}$. The smaller hills are superimposed on the larger abyssal hills and have a relief of about 50-100 m and a spacing of about 5-6 km. Several small seamounts (2 $\mathrm{km}$-wide, $300 \mathrm{~m}$-high) are scattered about the region. The largest seamount is located $\sim 3-4 \mathrm{~km}$ south of the coring site.

The coring site is located within magnetic polarity Chron $34 \mathrm{n}$ so the crustal age may range from 84 - 124.6 Ma (Gradstein and Ogg, 2002). Based on a tectonic reconstruction of the region (Larson et al., 2002), the crust was accreted along the Pacific-Phoenix spreading center $\sim 95 \mathrm{Ma}$ ago at ultra-fast spreading rates ( $\sim 90 \mathrm{~km} / \mathrm{Ma}$, half-rate). The sediment on which the nodule rested (half-buried) was homogeneous dark brown clay with micronodules and no microfossils seen on a smear slide. The nodule described in this study was approximately spherical (diameter was $65-68 \mathrm{~mm}$ as obtained from nine measurements along three axes) and was observed shipboard to be partially buried in sediment at the top of the sediment core. However, the actual orientation of the nodule at the seafloor is not known. The sample was collected as part of a much larger effort to document the nature of life in slowly-accumulating sediments of low primary productivity and great age.

A polished petrographic thin section of the nodule was prepared by Spectrum Petrographics, Inc. The nodule was embedded in 3M Scotchcast \#3, mounted on a fused silica slide with Loctite Impruv 363 adhesive, and sectioned to a $30 \mu \mathrm{m}$ slice and diamond-polished to an electron-microprobe finish. In addition, $1 \mathrm{~mm}$-thick sections were made and cut into $2 \mathrm{~mm}$ wide "matchsticks" for X-ray tomography, wet-chemical analysis and $\mu$ XRD. 


\subsubsection{Chemical composition}

160 The "matchstick" nodule sample was sectioned length-wise into 10 sub-samples using a microdrill device (Micromill@). Each fraction was dissolved in a mixture of $6 \mathrm{~mL}$ concentrated $\mathrm{HNO}_{3}$ (sub-boiled) and $2 \mathrm{~mL}$ concentrated HF (Trace metal or Optima grade) to ensure complete

163 dissolution of silicate phases. Solutions were evaporated on hot plates at $80^{\circ} \mathrm{C}$. Dry residues were

164 then dissolved in $5 \mathrm{~mL}$ concentrated $\mathrm{HNO}_{3}$ and $5 \mathrm{~mL} 6 \mathrm{M} \mathrm{HCl}$ and evaporated to dryness at

$16580^{\circ} \mathrm{C}$. This last step was repeated once to ensure completed dissolution of non-siliceous materials

166 including fluorides that could have formed during the first digestion step. Archive solutions were

167 kept in $5 \mathrm{~mL} 6 \mathrm{M} \mathrm{HCl}$. Elemental concentrations were measured on an ICP-AES (Inductively

168 Coupled Plasma Atomic Emission Spectroscopy) instrument, HORIBA Jobin YVON, ULTIMA

169 2) operated by Pôle-Spectrométrie-Océan (PSO, Ifremer/IUEM, Brest, France). Calibration of the

170 concentrations during analysis was done using a multi-elemental solution. As a consistency

171 check, two geostandards of nodule samples (USGS Nod P1 and USGS Nod A1) were analyzed

172 alongside our samples. The results, shown at the bottom of Table 1, are consistent with published

173 data (Axelsson et al., 2002).

174 Due to the process involved in micro-drilling and ICP-AES analysis, and potential dilution by

175 embedding resin, the nodule material could not be accurately weighed, but about $10 \mathrm{mg}$ was

176 collected for each subsample. Therefore, for consistency and comparison with electron

177 microprobe geochemical data, we did not report ICP-AES data in microgram of element per gram

178 of rock as it is the common usage in geochemistry, but instead data were normalized to $\mathrm{Fe}$ and

179 expressed in grams of element per gram of Fe. We defined two different zones in the nodule, the

180 "inner" and the "outer" nodule zones. The "outer" zone corresponds to the most external layers

181 including the surface directly in contact with ambient seawater. Therefore, the "inner" zone is

182 also the oldest and the "outer" zone is the youngest zone of the nodule. These zones are

183 morphologically distinct, as shown in Figures 1 and 3 and discussed below. Note that our section

184 of the nodule does not include the part in contact with the nucleus.

185 The fine-scale elemental composition and mineral textures was examined with electron

186 microprobe analysis using a JEOL JXA-8900 Electron Probe Microanalyzer and wavelength-

187 dispersive spectrometer at the Electron Microprobe Laboratory, Earth Science Department,

188 University of Minnesota.

189

$190 \quad 2.2 \quad$ Nodule material relative age estimates and apparent growth rate

$191 \quad 2.2 .1 \quad{ }^{9} \mathrm{Be} /{ }^{10} \mathrm{Be}$ systematics 
Most relative age estimates and apparent growth rates of Fe-Mn nodules have been

193 constrained by relying on the unique characteristics of the ${ }^{9} \mathrm{Be} /{ }^{10} \mathrm{Be}$ system in oceanic

194 environments (Graham et al., 2004). The delivery of ${ }^{9} \mathrm{Be}$ (the stable Be isotope) and ${ }^{10} \mathrm{Be}$ (a long-

195 lived radioisotope of Be with a half-life of $\sim 1.38$ Mya) to well-mixed deep ocean waters and

196 their subsequent incorporation into growing Fe-Mn nodules can be used as a proxy for the

197 relative ages of nodule sections when differences in the concentration of ${ }^{10} \mathrm{Be}$ or ${ }^{9} \mathrm{Be} /{ }^{10} \mathrm{Be}$ ratio

198 with depth in the nodule are known (Graham et al., 2004; Segl et al., 1989). Although many

199 processes contribute to the ultimate concentrations and ratios of ${ }^{9} \mathrm{Be}$ and ${ }^{10} \mathrm{Be}$ in ocean waters,

200 two important general principles apply: 1) the delivery of ${ }^{9} \mathrm{Be}$ to oceans is primarily from

201 terrestrial sediments and is thus (at least outside of sediment plumes at continental shelves)

202 influenced by globally averaged erosion rates, and 2) the delivery of $10 \mathrm{Be}$ to oceans is primarily

203 due to direct deposition after cosmogenic production in the upper atmosphere (due to spallation

204 reactions involving high-energy cosmic particles and gaseous $\mathrm{O}$ and $\mathrm{N}$ atoms) and is therefore

205 dependent on the long-term variation of solar activity (Willenbring and von Blanckenburg,

206 2010d) Both of these factors are known to vary over time, however ratios appear to vary around

207 a long-term mean (Willenbring and von Blanckenburg, 2010a) and growth rate estimates from

$208{ }^{10} \mathrm{Be}$ remain the major tool available to constrain and assess differences in ferromanganese nodule 209 growth behavior due to environmental factors.

\subsubsection{Chemical extraction and determination of ${ }^{9} \mathrm{Be}$ and ${ }^{10} \mathrm{Be}$ concentrations}

${ }^{9} \mathrm{Be}$ and ${ }^{10} \mathrm{Be}$ concentrations were determined in two increments between 0-5 mm and 15215 respectively). Material from these increments was extracted in three parallel sections - the middle 216 material was used for ${ }^{10} \mathrm{Be}$ determination and the two outer sections used for ${ }^{9} \mathrm{Be}$ determination.

$217{ }^{9} \mathrm{Be}$ was determined by digesting approximately $0.25 \mathrm{~g}$ of ground nodule material in $6 \mathrm{M}$

$218 \mathrm{HCl}$ for $3 \mathrm{hrs}$ at $110{ }^{\circ} \mathrm{C}$. Samples were analyzed in a Thermo Scientific XSERIES 2 ICP-MS with

219 ESI PC3 Peltier cooled spray chamber, SC-FAST injection loop, and SC-4 autosampler (Aqueous

220 Geochemistry Laboratory, Earth Science Department, University of Minnesota). Samples were

221 diluted $20 \times$ and $20 \mathrm{ppb}$ of $\mathrm{Y}$ internal standard was added. ${ }^{10} \mathrm{Be}$ was extracted from the nodule 222 material through a series of acidification steps and cation column chromatography prior to being 223 oxidized and analyzed by AMS. The methodology used here is modified from Ebert et al. (2012). 224 Approximately $0.25 \mathrm{~g}$ of ground nodule material was digested in Teflon vessels with $6 \mathrm{M} \mathrm{HCl}$ 225 and $250 \mu \mathrm{g}$ of spiked ${ }^{9} \mathrm{Be}$ carrier at $110^{\circ} \mathrm{C}$ for $3 \mathrm{hr} .4 \mathrm{ml}$ of $\mathrm{HF}$ was added to the cation solution in 
two steps to bind excess $\mathrm{Ca}$ and $\mathrm{Mg}$. After each $\mathrm{HF}$ addition step, $2 \mathrm{~mL}$ of ultrapure $\mathrm{H}_{2} \mathrm{O}_{2}$ was added to remove organics. The ultrapure water containing Be and other cations was removed from the fluoride cake via centrifugation and pipetting. Ion exchange chromatography (both anion and cation removal steps) was used to purify Be cations from the bulk cation solution. Behydroxides were precipitated from the purified cation solution by titration to $\mathrm{pH} 9$ through the addition of ammonium hydroxide. The supernatant was decanted and the precipitate was washed several times with ultrapure water and dried overnight at $100{ }^{\circ} \mathrm{C}$ in low-boron quartz vials. The

233 dry precipitate was flame-oxidized at $>850{ }^{\circ} \mathrm{C}$ to form $\mathrm{BeO}$ powder and pressed into cathodes for 234 AMS analysis at PRIME Lab, Purdue University, USA.

\subsubsection{Growth Rate Estimation}

Nodule growth rate was estimated by the ${ }^{10} \mathrm{Be}$ dating method developed for ferromanganese nodule segments ((Baturin and Savenko, 1989; Graham et al., 2004; Somayajulu, 2000). This dating method is based on the relative difference in isotopic composition of two layers (Graham et al., 2004):

Age difference $=\left(t_{1 / 2} / \ln (2)\right) \ln (I / O)$

where $t_{1 / 2}$ is the half-life of ${ }^{10} \mathrm{Be}$, and $I$ and $O$ are the isotopic composition of the "inner" and "outer" increments, respectively. The average growth rate between segments can then be determined by dividing the age difference by the distance across the nodule cross-section measured between segment centroids. Several previous growth rates reported for ferromanganese nodules used the older half-life estimate for ${ }^{10} \mathrm{Be}$ of $1.5+/-0.1 \mathrm{Ma}$.(Bhat et al., 1973). Here, we report absolute growth rate estimates using the revised consensus half-life for ${ }^{10} \mathrm{Be}$ (Chmeleff et al., 2010; Korschinek et al., 2010) of 1.387 Ma and also report apparent growth rate estimates using the former value of 1.5 Ma to facilitate direct comparison with previous work (i.e. Graham et al., 2004). The major assumptions of this equation is that the layers concerned had the same initial isotopic concentration when they were formed, and that there has been no isotopic exchange or fractionation since that time.

Some authors have applied the isotopic ratio of ${ }^{10} \mathrm{Be} /{ }^{9} \mathrm{Be}$ of the segments, instead of bulk 257 ratio of seawater is more invariant over time than the absolute ${ }^{10} \mathrm{Be}$ concentration (Graham et al., 258 2004; Segl et al., 1989). Therefore, we report age differences and growth rates here from based on 259 both the Be isotopic ratio and absolute ${ }^{10} \mathrm{Be}$ concentrations. 


\section{$2.3 \mu \mathrm{XRF}, \mu \mathrm{XAS}$, and $\mu \mathrm{XRD}$}

In order to study the morphology and element distributions in more detail micro X-ray fluorescence $(\mu \mathrm{XRF})$ maps were acquired at Beamline 10.3.2 of the Advanced Light Source (Marcus et al., 2004a). For a general survey, a long map was acquired over a strip $20 \mathrm{~mm}$ long by $1 \mathrm{~mm}$ wide, with $20 \mu \mathrm{m}$ pixels. All $\mu \mathrm{XRF}$ maps on the nodule were acquired at $10 \mathrm{keV}$, using dwell times of 30-50 ms and pixel sizes of 5-10 $\mu \mathrm{m}$. Fluorescence emission signals for Fe, Mn, $\mathrm{Ni}, \mathrm{Cu}, \mathrm{Zn}, \mathrm{Ti}, \mathrm{Ca}$, and additionally in some areas $\mathrm{Ce}, \mathrm{V}, \mathrm{P}$ and $\mathrm{Co}$ were recorded with a sevenelement Ge solid state fluorescence detector (Canberra).

Micro-X-ray absorption spectra ( $\mu \mathrm{XAS})$ at the Fe, $\mathrm{V}$ and Ti K-edges were recorded in fluorescence mode on selected spots of the $\mu$ XRF maps. The energy was calibrated with respect to the respective metal foils, whose inflection-point energy were taken to be $7110.75(\mathrm{Fe})$, $5463.76(\mathrm{~V})$ and $4966.40 \mathrm{eV}(\mathrm{Ti})$ respectively. Data were calibrated, deadtime-corrected, preedge subtracted and post-edge normalized using custom LabVIEW programs available at the beamline (https://sites.google.com/a/lbl.gov/microxas-lbl-gov/software). The data range for micro X-ray absorption near edge structure ( $\mu$ XANES) spectroscopy was $100 \mathrm{eV}$ below up to $300 \mathrm{eV}$ above the edge, while micro extended X-ray absorption fine structure ( $\mu$ EXAFS) spectroscopy data were taken up to $500 \mathrm{eV}$ above the edge. Fe $\mu$ XANES spectra were fit by least-square linear combination (LCF) to a large Fe database (Marcus et al., 2008). Overabsorption is significant in the more Fe-rich spots, and is taken as a free parameter in a simple model (planar, thick sample). Since the cited paper was published, a number of new spectra were added, including one for feroxyhite, a potentially-important species for nodules. This sample was prepared by the method of Schwertmann and Cornell (2000) and verified by powder XRD at the Characterization Facility, University of Minnesota, using a Siemens D-500 diffractometer with cobalt source. The observed $[\mathrm{Si}] /[\mathrm{Fe}]$ ratios in the nodule are low enough to rule out the presence of a significant (>10\%) amount of clays or most other silicates, so these were omitted from the set of fitting references. For $\mathrm{V}$ and $\mathrm{Ti}$, our libraries are much more limited. For Ti, the only standard we had whose XANES was at all similar to that of the sample was ilmenite. For $\mathrm{V}$, we used samples of $\mathrm{V}(\mathrm{V})$ sorbed on $\delta-\mathrm{MnO}_{2}$ and ferrihydrite. Hexagonal birnessite $\left(\mathrm{K}_{0.5} \mathrm{Mn}_{2} \mathrm{O}_{4} \cdot 1.5 \mathrm{H}_{2} \mathrm{O}\right)$ was synthesized by published methods (McKenzie, 1971;

291 hexagonal birnessite was prepared by boiling a $2.5 \mathrm{~L}$ solution of $0.4 \mathrm{~mol} / \mathrm{L} \mathrm{KMnO}_{4}$ with vigorous 292 mechanical stirring. The precipitate was formed through drop wise addition of $163 \mathrm{~mL}$ of 
concentrated $\mathrm{HCl}$ using a burette. $\mathrm{V}$ adsorption experiments were performed using goethite and 2line ferrihydrite, synthesized by standard procedures (Schwertman and Cornell, 1991).

The precipitates were washed in 3 centrifuge-resuspend cycles with purified water, separated from suspension using vacuum filtration ( $0.22 \mu \mathrm{m}$ Millipore polyethersulfone), and then freeze dried and stored as a dry power.

Fe micro-EXAFS spectra were analyzed with $k^{3} \chi(k)$ weighting, out to $\mathrm{k}=11 \AA^{-1}$. For those spectra in which over-absorption was significant, we performed LCF of the XANES spectra

$0.7293 \AA$ ) and 240 s acquisition time. The patterns were radially-integrated and calibrated using alumina powder and fit2D software (Hammersley, 1997). Micro XRD patterns were recorded at the $\mu \mathrm{XAS}$ spot locations on the thin sections, and on a nearby blank spot on the silica substrate so as to background subtract the data. In order to improve the sensitivity of the XRD, we also mounted a thick section ("matchstick") in such a way that the beam passed through $\sim 1 \mathrm{~mm}$ of

\subsection{Fe isotope analyses} (Inductively-Coupled-Plasma Mass-Spectrometer) (Neptune, Thermo-Scientific) at PôleSpectrométrie-Océan (PSO, Ifremer/IUEM, Brest, France) on the 10 subsamples of the nodule analyzed for the bulk geochemistry (see section 2.1.2). After chemical separation of Fe from the matrix through chromatography columns filled with an anion-exchange resin AG1-X8, ${ }^{56} \mathrm{Fe} /{ }^{54} \mathrm{Fe}$ 
instrumental mass discrimination combined with a standard-sample-bracketing method (Albarède and Beard, 2004; Rouxel et al., 2008; Rouxel et al., 2005) This analysis scheme allows us to determine a two standard deviation of 0.07-0.09 \%o based on replicate measurements of IRMM14 isotopic standard. ${ }^{56} \mathrm{Fe} /{ }^{54} \mathrm{Fe}$ isotope ratios of samples are reported relative to IRMM-14 Reference Material according to the conventional delta notation (1) used for stable isotope systematics. single mass fractionation line and only $\delta^{56 / 54} \mathrm{Fe}$ values are discussed in this paper. The iron isotope composition of the USGS geological reference material nodule (Nod-A-1), yielding $\delta^{56 / 54} \mathrm{Fe}=-0.37 \pm 0.06(2 \mathrm{sd}, \mathrm{n}=12)$ is consistent with previously published data (Dideriksen et al., 2006). We also determined the long-term average value of Nod-P-1 USGS geological reference material and obtained $\delta^{56 / 54} \mathrm{Fe}=-0.51 \pm 0.09(2 \mathrm{sd}, \mathrm{n}=11)$. Results for NodA-1 and Nod-P-1 reported in Table 1 correspond the $\delta{ }^{56 / 54} \mathrm{Fe}$ values obtained within the same analytical conditions than for the nodule samples obtained after micro-drilling.

\section{Results}

\subsection{Nodule growth rate}

The chronometer we used was based on two Be isotopes. ${ }^{9} \mathrm{Be}$ and ${ }^{10} \mathrm{Be} .{ }^{10} \mathrm{Be}$ is a radioactive nuclide produced in the atmosphere (cosmogenic nuclide). The production rate of ${ }^{10} \mathrm{Be}$ in the atmosphere is presumably constant and when this flux reaches the oceans through aerosol rainfall, it mixes with ${ }^{9} \mathrm{Be}$ present in the oceans after riverine inputs. The seawater isotope ratio of ${ }^{10} \mathrm{Be} /{ }^{9} \mathrm{Be}$ has remained constant in modern oceans (Willenbring and von Blanckenburg, 2010a, d), and therefore when nodules precipitate from seawater they incorporate Be which has the same ${ }^{10} \mathrm{Be} /{ }^{9} \mathrm{Be}$ ratio as ambient seawater. ${ }^{10} \mathrm{Be}$ decays with a half of $1.39 \mathrm{Ma}$ (Chmeleff et al., 2010), therefore as the nodule grows, ${ }^{10} \mathrm{Be} /{ }^{9} \mathrm{Be}$ ratios in the older layers of the nodule will decrease and using the exponential law of radioactive decay we can reconstruct an age model for the different layers in the nodule.

The ${ }^{9} \mathrm{Be}$ and ${ }^{10} \mathrm{Be}$ values for the nodule are displayed in Table EA1. Both ${ }^{9} \mathrm{Be}$ and ${ }^{10} \mathrm{Be}$ concentrations for this nodule $\left(3.6-3.8 \mathrm{mg} / \mathrm{kg}\right.$ and $0.54-3.41 \times 10^{9}$ atoms $\mathrm{g}^{-1}$, respectively) fall within the range of concentrations reported in previous publications (Segl et al. 1989; Graham et al. 2004). The growth rates estimated for this nodule (from $3.8 \pm 0.7$ to $4.2 \pm 0.7 \mathrm{~mm} / \mathrm{Ma}$ ) using 
multiple estimation methods appear to be slightly lower than the range of rates reported in Graham et al. 2004 (4.7 - $32 \mathrm{~mm} / \mathrm{Ma})$, but are well within the range of globally compiled estimates (1.24 - $5.17 \mathrm{~mm} / \mathrm{Ma}$ ) from Willenbring and von Blanckenburg (2010a).

\subsection{Chemical composition}

The chemical composition of the South Pacific Gyre-2 (SPG-2) nodule, as determined by analyses of 10 increments spanning the $19.5 \mathrm{~mm}$ radius of the nodule in 1 to $3 \mathrm{~mm}$ lengths, is displayed in Table 1. All elemental concentrations are normalized by Fe. In addition to the bulk average of the 1 to $3 \mathrm{~mm}$ increments, Electron Microprobe Analyzer (EMPA) was used to measure fine-scale elemental composition in three transects displayed in Figure 1. The EMPA data are expressed in wt \%, but note that the sum of the weights does not equal $100 \%$ because the nodule is porous, rich in hydrous mineral phases, and $\mathrm{CO}_{2}$ (Tables EA2, EA3).

Figure 2 shows a ternary plot of $\mathrm{Mn}, \mathrm{Fe}$ and $(\mathrm{Ni}+\mathrm{Co}) \times 10$ and displays the properties distinguishing among hydrothermal, hydrogenetic, and diagenetic sourced marine Fe/Mn-rich deposits. The three numbers represented by a point in this plot are $X_{\mathrm{Fe}}=[\mathrm{Fe}] /([\mathrm{Fe}]+[\mathrm{Mn}]+([\mathrm{Ni}]+[\mathrm{Co}]) \quad \times 10), \quad X_{\mathrm{Mn}}=[\mathrm{Mn}] /([\mathrm{Fe}]+[\mathrm{Mn}]+([\mathrm{Ni}]+[\mathrm{Co}]) \quad \times 10), \quad$ and $X_{\mathrm{NiCo}}=(([\mathrm{Ni}]+[\mathrm{Co}]) \times 10) /([\mathrm{Fe}]+[\mathrm{Mn}]+([\mathrm{Ni}]+[\mathrm{Co}]) \times 10)$, with $[.$.$] representing atomic percentages.$ The left-hand corner represents $X_{\mathrm{Fe}}=1$, the right-hand corner $X_{\mathrm{Mn}}=1$, and the top $X_{\mathrm{NiCo}}=1$, which implies that $X_{\mathrm{Fe}}+X_{\mathrm{Mn}}=0.9$. Note that this representation works even using data normalized by [Fe]. Three types of data were compared: (1) the EMPA data for "inner" and "outer" transects (as defined in Figure 1b, c); (2) the bulk average ICP-AES data for the 1 to $3 \mathrm{~mm}$ increments; and (3) selected literature data for the North and South Pacific Ocean (Halbach et al., 1981). Oceanic metalliferous deposits that have a high diagenetic component plot in the "diagenetic field" of the ternary diagram of Figure 2 (i.e. high Mn content and a trend towards higher $\mathrm{Ni}+\mathrm{Co}$ ), deposits that have a hydrothermal contribution have generally low $\mathrm{Ni}+\mathrm{Co}$ contents but variable $\mathrm{Mn}$ and Fe contents ("hydrothermal field"), and finally the "hydrogenetic field" contains deposits formed from seawater and they are characterized by high $\mathrm{Ni}+\mathrm{Co}$ and the proportions of $\mathrm{Mn}$ and Fe in these deposits are relatively similar. Northern Pacific nodules generally have a diagenetic contribution, as shown by the trend towards higher $\mathrm{Mn} / \mathrm{Fe}$ and $(\mathrm{Ni}+\mathrm{Co}) / \mathrm{Fe}$, whereas the SPG-2 nodule displays a trend toward a hydrogenetic contribution (lower $\mathrm{Mn} / \mathrm{Fe}$ and $(\mathrm{Ni}+\mathrm{Co}) / \mathrm{Fe}$ content). Together with reference datasets, the SPG-2 composition indicates that it was primarily a hydrogenetic deposit throughout its growth history. This finding is consistent with the documented low flux of organic matter to the seafloor of the South Pacific Gyre (Jahnke, 1996) and reduced diagenetic contributions to the growth of the SPG-2 nodule. 


\subsection{Nodule morphology and trace element distributions}

Backscatter scanning electron microscopy and electron microprobe analyses revealed morphological differences between "inner" and "outer" zones of the nodule (Figure 1, 2). In

"botryoidal" morphology of concentric, layered mineral growth and a porous "matrix" material between the botryoids. These growth habits have been previously reported (Halbach et al., 1981).

A tricolor $\mu$ XRF map showing the distributions of Fe, Mn and Ni from the "outer" to "inner" zone is displayed in Figure 3 along with a photomicrograph and the fluorescence counts for $\mathrm{Fe}, \mathrm{Mn}$ and $\mathrm{Ni}$ along the nodule radius. A clear transition in the elemental composition was observed at approximately $12 \mathrm{~mm}$ : Fe increased and Mn decreased along the transect toward the nodule center. These results are consistent with the EMPA Mn/Fe data (Table EA3) but not with the bulk average ICP-AES data for the 1 to $3 \mathrm{~mm}$ increments. Bulk ICP-AES analyses of the 10 subsamples of the nodule do not show significant variations in metal/Fe (Table 1) across the nodule transect, suggesting uniform metal/Fe ratios in Fe and Mn-rich phases at the scale of sampling intervals (1 to $3 \mathrm{~mm}$ ). Bulk ICP-AES analyses suggest the geochemical composition of the nodule is homogenous at the bulk $(1-3 \mathrm{~mm})$ scale, while $\mu$ XRF and EMPA data reveal a finescale geochemical variability along the nodule, not captured by millimeter-scale analyses.

Some trace elements, notably Ti, V and, to a lesser extent, Zn, are associated with Fe in the nodule (EMPA data; Figure 4; V shown in Figure 5.). Micro-XRF maps of the "inner" and "outer" zones, displayed in Figure 5, also show this pattern. For Ti and V, the correlation with $\mathrm{Fe}$ is good, as viewed in red-blue bicolor maps of Fe+Ti (correlation coefficient 0.78 for "inner" and 0.92 for "outer") and Fe+V (correlation coefficient 0.86 for inner and 0.85 for outer) (Figure 6), in which the hue is nearly uniform. Note that the Fe+Ti correlation for "inner" came from the same XRF map as the Fe+V correlation for "inner", so cover the same number of independent pixels. The same is true for the Fe+Ti and Fe+V correlations in "outer". Since these numbers derive from pixel-by-pixel scatterplots, it is difficult to define the number of statisticallyindependent points since the samples have features which are much bigger than a pixel. When Fe is shown as blue and Ti or V in red, the matrix shows slightly bluer than the "botryoids", indicating a slightly lower $(\mathrm{V}, \mathrm{Ti}) / \mathrm{Fe}$ ratio in the matrix than elsewhere. For Ti, the difference in ratio is about $20 \%$, while the two types of material differ in $\mathrm{V} / \mathrm{Fe}$ ratio by only $6 \%$. The inverse correlation between $\mathrm{Ti} / \mathrm{Fe}$ and $\mathrm{Mn} / \mathrm{Fe}$ ratios (Figure 4d) in the "inner" zone indicates that $\mathrm{Ti}$ is mostly associated with $\mathrm{Fe}$. The distribution of $\mathrm{Zn}$ also has some features in common with that of Fe, in particular, an enrichment in the "matrix" areas (Figure 5). These patterns of distribution 
are consistent with Ti and V bound to or incorporated in Fe-bearing mineral phases in the "botryoids", and Zn bound to or incorporated in Fe-bearing mineral phases in the "matrix".

Clear correlations in $\mathrm{Ni} / \mathrm{Fe}$ and $\mathrm{Co} / \mathrm{Fe}$ ratios versus $\mathrm{Mn} / \mathrm{Fe}$ suggest that $\mathrm{Ni}$ and $\mathrm{Co}$ are hosted primarily by Mn-rich minerals (Figure 4a, b). The scatter in the $\mathrm{Zn} / \mathrm{Fe}$ versus $\mathrm{Mn} / \mathrm{Fe}$ data indicates that $\mathrm{Zn}$ may be associated with both Mn and Fe mineral phases (Figure 4c). The $\mu$ XRF data in Figure 5 corroborate this finding by showing spatial correlation of $\mathrm{Zn}$ with both $\mathrm{Fe}$ - and Mn-rich features.

From a morphological perspective, the "botryoidal" features are much more pronounced in the "outer" zone of the nodule than in the "inner" zone (e.g. Figure 5). In contrast, the Fe-rich "matrix" found in between the "botryoidal" microstructures is a more prominent morphology in the "inner" zone. These growth patterns, as well as the elemental composition, along the radius of the SPG-2 nodule form the basis for our definition of "outer" and "inner" zones having dominant "botryoidal" and "matrix" morphologies.

\subsection{Fe-bearing phases}

\subsubsection{Matrix features}

The EXAFS data (Fourier transform) and fits are shown in Figure 7 along with XRF maps indicating the locations at which the spectra were taken. The data did not differ substantially among various locations within a given zone.

The Fourier transform in Figure 7b shows the data for the "inner" zone locations overplotted with a linear-combination fit using $39 \%$ feroxyhite $(\delta$-FeOOH $)$ and $53 \%$ goethite $(\alpha$ $\mathrm{FeOOH}$ ). Although this fit is a good match to the data, it does not rule out the presence of a few percent of other species. The phase of higher-shell peaks agrees with those in the fit out to $6 \AA$, presumably due to the long-range order of crystalline goethite. While $\mu \mathrm{XRD}$ was not done on these specific spots, patterns taken at other matrix spots confirm the presence of goethite.

The "matrix" in the "outer" zone is typified by the spectrum and fit shown in Figure 7a. This spectrum fits well to $28 \%$ lepidocrocite $(\gamma-\mathrm{FeOOH}), 39 \%$ disordered biogenic oxide (Toner et al., 2009), and $18 \%$ goethite. Although the reference material we call "biogenic oxide" is indeed biogenic, this reference represents highly-disordered Fe oxyhydroxide from any source, biogenic or not. The XANES also fits to the same three minerals, but in proportions of $46 \%, 21 \%$ and $30 \%$, respectively. However, no diffraction measurements on any spot show the strong basal $(020, d=6.26 \AA$ ) reflection expected for lepidocrocite (Figure 8). We refer to this reflection as "basal" because lepidocrocite has a layered structure consisting of sheets of edge-sharing octahedra, with the conventional $c$-axis as the layering direction. Other lepidocrocite reflections 
come close enough to those from other phases such as goethite to make their identification uncertain. The basal reflection, however, is one of the strongest and should therefore appear if well-crystalline lepidocrocite were common in our samples.

The feature in the EXAFS spectrum, that seems to point to lepidocrocite is the prominent peak at $2.7 \AA$ (Figure 7a), which corresponds to edge-sharing $\mathrm{FeO}_{6}$ octahedra. The lepidocrocite structure consists of layers of edge-sharing octahedra. The inter-layer spacing gives rise to the basal reflection, which is not found by $\mu \mathrm{XRD}$ in our samples at any spot. Thus, what the EXAFS indicates is that the material has a large fraction of edge-sharing octahedra relative to a ferrihydrite-like phase or goethite. Shell-by shell fitting yields an average Fe-O distance in the first shell of $2.01 \pm 0.015 \AA$, an Fe-Fe shell $3.06 \pm 0.03 \AA$ with a coordination number between 2 and 6 (highly uncertain due to correlation with $\Delta \sigma^{2}$ ), and a weak third Fe-Fe shell at $3.38 \pm 0.04$ $\AA$. The coordination number of this shell is extremely uncertain due to correlation with $\Delta \sigma^{2}$, but the fit is significantly better with this shell included. The Fe-Fe distances correspond nicely to edge- and corner-sharing octahedra. By comparison, the edge-sharing distance in lepidocrocite is $3.067 \AA$ and the corner-sharing distances in goethite are $3.30 \AA$ and $3.47 \AA$. In addition, shells at apparent distances of $\sim 3.6 \AA$ and $4.6 \AA$ match those experimentally found for lepidocrocite, and correspond to $\mathrm{Fe}-\mathrm{Fe}$ distances within the layers. The EXAFS evidence, and apparent lack of the lepidocrocite (002) reflection, is consistent with lepidocrocite nanoparticles that are thin in the $c$ direction but transversely large enough to show the high shells in EXAFS. Note that the biogenic oxide we used as a reference material also has a relatively large ratio of edge-sharing to cornersharing octahedra, but the overall intensity of that shell is smaller than what we find for the lepidocrocite-like material.

\subsubsection{Botryoidal features}

The abundance of "botryoidal" material varies between the "inner" and "outer" zones. Principal components analysis (PCA) of Fe EXAFS data from the spots displayed in Figure 9 reveals a two component system. The spectra can be represented as weighted sums of signals from two materials. The first component is similar to that found for the "inner" matrix and is a combination of feroxyhite and goethite. The second component does not fit to a sum of our reference spectra. The nature of this component is explored below.

Spots 5 and 1 from the "inner" zone (Figure 9b) are the best examples of the "botryoidal" Fe material. The Fourier transformed EXAFS signal for Spot 5 are shown in Figure 10. There are strong peaks at distances similar to those found for corner- and edge-sharing octahedra. The best fit for this spectrum contains four contributions. One is an Fe-O shell 
represented as the Fe-O first neighbor from feroxyhite. While the Fe-O shell is actually split, the data do not cover a long enough $k$-range to resolve this splitting, and the first shells of our models are well-represented as single shells. Next is a Fe-Fe shell at $3.04 \pm 0.038 \AA$ with a coordination number $(\mathrm{CN})$ of 2.3-9. The distance found for this shell is consistent with edge-sharing octahedra such as those found in lepidocrocite (3.06 $⿱$ ) ), whose edge-sharing peak was used as an experimental reference. This contribution requires an additional mean-square relative displacement (MSRD, second moment of the distance distribution) of 0.014-0.047 $\AA^{2}$, beyond that found in lepidocrocite. This is a significant dispersion, which may reflect an unresolved splitting. The large error bars on this number and the $\mathrm{CN}$ reflect parameter correlation between the two. It was found necessary to add a contribution from goethite, which was used without any adjustment except for amount and included all shells out to $3.5 \AA$ A. The result showed that 10 $25 \%$ of the $\mathrm{Fe}$ in the sample had to be assumed to be in the form of goethite, though it is possible that some of the other oxides would provide an acceptable fit in this role. Note that the coordination numbers quoted above and below for non-goethite Fe-Fe shells is the average over all Fe atoms; they should be divided by "1-(goethite fraction)" to get the Fe-Fe CNs in the 75$90 \%$ of the spot 5 material that is not goethite. A fit with only these three contributions always showed a discrepancy in the FT at around $3.3 \AA$ (apparent). While the phase would match, the amplitude did not. To solve this problem, an additional Fe-Fe shell at $3.45 \pm .0 .04 \AA$ (CN 0.25$0.9)$ was added to the fit. This distance is comparable to the longer corner-sharing distance in goethite (3.47 $\AA$ ), thus we interpret it as coming from corner-sharing octahedra in the nongoethite fraction. The MSRD of this shell was assumed to be the same as that in the reference lepidocrocite edge-sharing shell, in order to reduce the number of free parameters. To summarize, the three contributions we find to the Fe environment are goethite, edge-sharing octahedra as in lepidocrocite, and a smaller number of corner-sharing octahedra. We were not able to identify the exact minerals containing these coordination polyhedra (except goethite).

The result of fitting is shown in the bottom panel of Figure 10, as the FT magnitude and imaginary part of the data compared with the fit, along with the FT magnitudes of the individual components in the top panel of Figure 10.

\subsection{Valence states of $\mathrm{Ti}$ and $\mathrm{V}$}

For Ti, three XANES spectra were taken at "matrix" points from within the "outer" zone. Titanium EXAFS was not possible due to the interference of the $\mathrm{Ba}_{3}$ edge, about $280 \mathrm{eV}$ above the $\mathrm{Ti} \mathrm{K}$-edge. The best match between the data and references was ilmenite $\left(\mathrm{FeTiO}_{3}\right)$, as shown in Figure 11. The match is not perfect; therefore, the Ti phase within the SPG-2 "outer" "matrix" 
is not literally ilmenite. Rather, the Ti is likely tetravalent and in octahedral coordination to oxygen which share edges with $\mathrm{FeO}_{6}$ octahedra: as in the ilmenite structure. Since the "matrix" is largely composed of goethite, which consists of edge-sharing Fe-O octahedra, it is plausible that the spectrum could be accounted for by Ti sorbed to or substituted within goethite.

Vanadium XANES spectra for points from the "inner matrix", "inner botryoid", and "outer botryoid" regions were collected. All of these spectra fit with a two-component model generated by Iterative Target Factor Analysis (ITFA). These two component spectra, ITFA0 and

537 ITFA1, are shown in Figure 12 along with spectra for $\mathrm{V}(\mathrm{V})$ sorbed to 2-line ferrihydrite and $\delta$ -

$538 \mathrm{MnO}_{2}$. Note that the pre-edge peak intensity is lower for $\delta-\mathrm{MnO}_{2}$-sorbed $\mathrm{V}$ than for ferrihydritesorbed V. Although the pre-peak height is often taken as a sign of valence state, both standards are pentavalent, and the difference is presumably due to the differing symmetry of the $\mathrm{V}$ site (Tanaka et al., 1987; Wong et al., 1984).

Figure 13 shows a trend in the $\mathrm{V}$ speciation as a function of the local Fe/Mn ratio. The use of the logarithm as the abscissa is not meant to imply any theory; it is for plotting

544 convenience only. In order to understand the trend, an analysis of the V spectral end-members

545 was attempted. Figure 14 displays fits of ITFA-derived end-member spectra to a combination of $546 \mathrm{~V}$-sorbed standards and, for ITFA0, $\mathrm{LaCl}_{3} \cdot 7 \mathrm{H}_{2} \mathrm{O}$, which is needed to represent a small amount of 547 La, whose intense white line makes for a sharp peak at $5489 \mathrm{eV}$. Vanadium-sorbed goethite (two 548 loadings) and hematite standards did not appear in the fits to either ITFA component. Component 549 ITFA0, which is most prominent in Mn-rich regions, is well-represented by a mixture of the two sorbed standards $(29 \% \mathrm{Mn}, 66 \% \mathrm{Fe}, 4 \% \mathrm{La})$, suggesting that $\mathrm{V}$ is hosted by the nanoparticulate oxides which form the bulk of the nodule. However, ITFA1, which is found in Fe-rich regions, 552 does not fit well. The best fit is to $\mathrm{V}$ on $\delta-\mathrm{MnO}_{2}$ alone, which seems odd as there is little $\mathrm{Mn}$ in 553 the areas in which ITFA1 is most prominent. In addition, the fit quality is not nearly as good as 554 for ITFA0. It is possible to improve the fit by adding such species as $\mathrm{VO}_{2}$ and $\mathrm{V}_{2} \mathrm{O}_{5}$, but it is 555 probable that such a combination merely reconstructs the spectrum without representing the true $556 \mathrm{~V}$ species. This is a common challenge with database-driven data fitting; the true species is likely 557 something missing from our database. If $\mathrm{V}$ were to be co-deposited in or sorbed on $\mathrm{Fe}$ 558 oxyhydroxide in octahedral symmetry, it might also have a low pre-peak. Therefore, the ITFA1 559 species is tentatively assigned to $\mathrm{V}$ in octahedral coordination to oxygen and sorbed to $\mathrm{Fe}$ 560 oxyhydroxides. It should be noted that an ITFA end-member may easily be a mixture of actual 561 species as the fit proved true in the case of the ITFA0 discussed above.

\section{$563 \quad 3.6 \quad$ Fe isotope composition}


Iron isotope composition along the nodule section yields a range of values from -0.16 to $0.07 \pm 0.09 \%$ ( 2 sd; Table 1$)$. The $\delta^{56 / 54} \mathrm{Fe}$ values are constant within uncertainty along the nodule radius with an average value of $-0.12 \pm 0.07 \%$ ( $2 \mathrm{sd}$ ) for the 10 increments analyzed. This means that constant Fe isotope values, when averaged over 1 to $3 \mathrm{~mm}$ increments or approximately 0.25 to $0.74 \mathrm{Ma}$ intervals, were observed over a period of $4 \mathrm{Ma}$. We observe that Fe in the "inner" part of the nodule is isotopically identical to Fe present in the "outer" part. Although our measurement interval is too coarse to resolve the isotopic signature of Fe-rich "matrix" versus Mn-rich botryoidal structures, our results are consistent with similar isotope values for "matrix" and "botryoids" because there is more "matrix" in the "inner" part and more "botryoids" in the "outer" part of the nodule, yet the isotope values are the same within experimental error. Moreover, the Fe isotopes recorded in the SPG-2 nodule are within the range of $\mathrm{Fe}$ isotope compositions reported for slowly precipitated hydrogenetic ferromanganese crusts ( -1.2 to +1.6\%) (Chu et al., 2006; Horner et al., 2015; Levasseur et al., 2004; Zhu et al., 2000).

\section{Discussion}

\subsection{Mineral structure and stability}

Our results indicate that the Fe speciation in the hydrogenetic South Pacific Gyre nodule is considerably more complex than expected and quite different from the uniform amorphous $\mathrm{FeOOH}$ "background" component typically discussed in the literature. Iron oxyhydroxides in the SPG-2 nodule are present in a wide variety of forms - goethite $(\alpha-\mathrm{FeOOH})$, goethite polymorphs feroxyhite $\left(\delta^{\prime}-\mathrm{FeOOH}\right)$ and nano-lepidocrocite $(\gamma-\mathrm{FeOOH})$, and biogenic-like ferrihydrite. Each of these phases is thought to form under different environmental conditions ( $\mathrm{pH}$ and $\mathrm{Eh}$, as examples). Therefore, although the SPG-2 nodule formed in a well-oxygenated environment, the diversity of phases observed should reflect either changes in the deep-sea environment at the sediment-water interface or mineral transformation processes over 3.65 to $4.05 \mathrm{Ma}$ of growth (Schwertmann and Cornell, 2000).

The major trend in Fe speciation within the "matrix" material is a positive correlation

594 Fe EXAFS data reveal that goethite is more abundant in the "inner" (older) deposits than in the

595 “outer" (younger) deposits, $53 \mathrm{~mol} \%$ and $18 \mathrm{~mol} \%$, respectively. Therefore, the SPG-2 nodule

596 hosts a series of phases in which the mineral stability of the Fe oxyhydroxides increases with the

597 age of the deposit. 
The "outer matrix" consists of goethite < lepidocrocite < biogenic-like ferrihydrite. Approximately $1 / 3$ of the "outer matrix" is a c-disordered lepidocrocite. Lepidocrocite is typically observed in low oxygen environments with $\mathrm{Fe}^{2+}$ present, and is meta-stable with respect to goethite (Schwertmann and Cornell, 2000). In general, the "outer matrix" is characterized by poorly-crystalline Fe oxyhydroxide phases consistent with those observed in modern lowtemperature, deep-sea deposits where microbial activity is evident (Toner et al., 2012; Toner et al., 2009). However, microbial activity is not a necessary condition for the precipitation of poorly-crystalline phases. For example, strongly sorbing ligands such as $\mathrm{P}, \mathrm{Si}$, and As produce $\mathrm{Fe}(\mathrm{III})$ precipitates with these characteristics, and transition metal impurities are known to slow recrystallization processes (Cornell et al., 1992). The structural characteristics and abundance of

615 1980). In poorly drained soils, where ferrihydrite, lepidocrocite, goethite, and feroxyhite are

616 observed within the profile, feroxyhite is associated with the Mn oxide vernadite (Birnie and

617 Paterson, 1991). While the conditions of feroxyhite formation in laboratory and field studies are

618 consistent with one another and with what we know of the SPG-2 nodule - precipitation in pore

619 spaces near Mn-rich phases - there is little consensus in early literature regarding the stability

620 relationship between feroxyhite and goethite. Chukhrov et al. (1977) proposed that feroxyhite is

621 meta-stable with respect to goethite. However, Carlson and Schwertmann (1980) concluded that

622 feroxyhite does not recrystallize to form goethite, but that the two phases form under different

623 conditions, namely fast oxidation of $\mathrm{Fe}^{2+}$ (feroxyhite) versus slow precipitation of $\mathrm{Fe}^{3+}$ (goethite).

624 More recently, the stability, and transformation time, for pure oxyhydroxides with respect to

625 hematite in the presence of trace $\mathrm{Fe}^{2+}$ was established as: ferrihydrite $\leq$ feroxyhite $<$ lepidocrocite

626 < akaganeite < < goethite (Lu et al., 2011). In agreement with Lu et al., when particle size and

627 mineral surface hydration are considered, goethite was most often the stable phase relative to

628 coarse hematite over a wide range of surface area/particle size conditions; however, at high

629 surface area values ferrihydrite can be the stable phase (Navrotsky et al., 2008). These results

630 may indicate that feroxyhite precipitated from a sediment source (fast oxidation of $\mathrm{Fe}^{2+}$ ), while

631 goethite precipitated in contact with ambient seawater (slow precipitation of $\mathrm{Fe}^{3+}$ ). In this 
conceptual framework, the presence of feroxyhite would reflect the "diagenetic" source of metals (sediment porewaters), while goethite would be indicative of the "hydrogenetic" source of metals (seawater dissolved trace metals).

Iron minerals with a known role for $\mathrm{Fe}^{2+}(\mathrm{aq})$ in their formation were observed in both the "inner" and "outer" matrix materials, feroxyhite and lepidocrocite, respectively. Given the overall hydrogenetic character of the nodule and the low biological productivity of the overlying waters, we do not have a good explanation for a source of $\mathrm{Fe}^{2+}$ (aq) or the presence of these minerals. While Fe is abundant in this depositional environment, our understanding of the seafloor conditions points to low availability of $\mathrm{Fe}^{2+}(\mathrm{aq})$. Two possible explanations for the presence of $\mathrm{Fe}^{2+}(\mathrm{aq})$ should be considered. First, the overall hydrogenetic character of the nodule does not rule out all contributions of material from the sediments. Second, even in low productivity waters there may be enough organic material delivered to the seafloor to promote some Fe reduction during the deposition of the "matrix" materials. We must conclude that either a very low supply of $\mathrm{Fe}^{2+}$ (aq) is sufficient to influence the mineralogy of these slowly accumulating deposits or that the presence of lepidocrocite and feroxyhite do not indicate an $\mathrm{Fe}^{2+}$ (aq) precursor.

The "botryoidal" material is a combination of crystalline minerals similar to those found in the "matrix", plus another material whose most distinctive feature is the presence of edgesharing octahedra with considerable dispersion in Fe-Fe distance. In the "botryoidal" microstructures, as opposed to the "matrix", there is considerable Mn in addition to the Fe. Thus, the possibility should be considered that we have a mixed phase in which the nearest cation neighbor to Fe is not always Fe but is sometimes $\mathrm{Mn}$, such as in "Fe-vernadite". However, the "botryoidal" material need not be a single phase, and could include Fe-rich and Mn-rich material too finely intergrown to have been resolved in this study. If the two phases have differing $\mathrm{Fe}-\mathrm{Fe}$ distances, then the resulting average EXAFS could show a large MSRD. However, because linear-combination fitting did not produce a match, at least one of these phases must be something not found in our spectral database. Consistent with intergrowth between $\mathrm{Mn}$ and $\mathrm{Fe}$ minerals, the "botryoidal" material includes several percent of other transition metals such as $\mathrm{Cu}$, $\mathrm{Ni}, \mathrm{Co}$ and $\mathrm{Zn}$, which are known to be associated primarily with Mn oxide minerals in hydrogenetic ferromanganese crusts (Halbach and Puteanus, 1984; Hein et al., 2003; Koschinsky and Halbach, 1995; Koschinsky and Hein, 2003; Koschinsky et al., 1997).

\subsection{Trace element association with Fe oxyhydroxides}


For the SPG-2 nodule, trace element distributions and speciation were determined by $\mu \mathrm{XRF}$ mapping and $\mu$ XANES, respectively. Trace elements Ti and V were co-located with the Fe-rich "matrix" materials of the "inner" and "outer" nodule. In contrast, transition metals $\mathrm{Ni}$, $669 \mathrm{Cu}$, and $\mathrm{Zn}$ are primarily co-located with $\mathrm{Mn}$ within the "botryoidal" materials of the "inner" and 670 "outer" nodule. These observations are consistent with a vast literature base demonstrating the 671 affinity of oxyanions such as V for Fe oxyhydroxide minerals, and the affinity of divalent cations 672 for Mn oxide minerals, in laboratory experiments and field observations (Brown et al., 1999; 673 Cornell and Schwertmann, 2003; Nicholson and Eley, 1997). More specifically, our $\mu$ XRF and $674 \mu \mathrm{XAS}$ observations build on previous investigations of hydrogenetic deposits that employed 675 operationally defined, wet-chemical approaches. A strong correlation between $\mathrm{Co}, \mathrm{Ni}, \mathrm{Cd}, \mathrm{Zn}$, $676 \mathrm{Cu}$ and $\mathrm{Mn}$ in a " $\delta-\mathrm{MnO}_{2}$ " phase was observed in hydroxylamine hydrochloride leaching 677 experiments (Koschinsky and Halbach, 1995). Similarly, Ti and V were correlated with an 678 "amorphous FeOOH" phase that dissolved in the presence of oxalic acid (Koschinsky and Halbach, 1995). Our X-ray microprobe observations confirm the interpretation of leaching experiments by showing that $\mathrm{Ti}$ and $\mathrm{V}$ are co-located with the Fe phases of the "matrix" throughout the SPG-2 nodule. In addition to co-location, Ti and V XANES results are most consistent with tetravalent $\mathrm{Ti}$ and pentavalent $\mathrm{V}$ in octahedral coordination to oxygen and adsorbed to Fe oxyhydroxides in the nodule. These associations did not vary along the growth radius of the nodule. Considering the evidence for mineral alteration over time, our Ti and $\mathrm{V}$ data indicate that trace metal speciation within the nodule is not over-written or erased as the minerals age to more stable phases. (Tables EA1 and EA2) decreases on going from "outer" to "inner", and the difference between the $\mathrm{Ti} / \mathrm{Fe}$ ratio in matrix vs. botryoids increases. We speculate that as the Fe minerals age and become more crystalline, Ti is expelled from surface or edge sites. This effect would depend on which Fe minerals are involved, so might be expected to differ between matrix and botryoidal material. An analogous effect has been seen for Ni in the goethite fraction of lateritic soil by

693 Dublet et al. (2015).

\subsection{Fe isotope composition along the nodule}

696

697 The biogeochemical cycling of Fe in the oceans has important implications for the biological 698 pump because Fe is a bio-limiting nutrient (Martin and Fitzwater, 1988). Thus, Fe bioavailability 699 in marine environments through time could have influenced the regulation of the carbon cycle. 
Iron is delivered to the oceans from continents by rivers, glaciers, and windblown particles (dust),

701 as well as by release from continental shelf sediments and hydrothermal venting (Raiswell and

702 Canfield, 2012). These sources of Fe have different $\delta^{56 / 54} \mathrm{Fe}$ values that are further modified by

703 chemical processes in the ocean (Beard et al., 2003; Chu et al., 2006; Conway and John, 2014;

704 Dauphas and Rouxel, 2006; Horner et al., 2015; John et al., 2012; Radic et al., 2011; Scholz et al.,

705 2014; Severmann et al., 2010). Hence, temporal Fe isotope variations in seawater, as recorded by

706 FeMn hydrogenetic deposits, may help deciphering the variability of Fe sources to the oceans

707 (Zhu et al., 2000; Chu et al., 2006; Horner et al., 2015). For instance, the Fe isotope composition

708 in a Pacific hydrogenetic ferromanganese crust over 76 Ma shows that deep Fe sources (e.g.

709 hydrothermal Fe) may have strongly influenced the Fe supply to the oceans over the Cenozoic

710 (Horner et al., 2015). These findings questioned the general assumption that aeolian dust particles

711 are the predominant source controlling the biogeochemical cycling of Fe in modern oceans.

712 However, because precipitation and adsorption processes as well as mineralogy can fractionate Fe

713 isotopes, our study provides a framework for understanding the relationships between fine-scale

714 mineralogical variability in a ferromanganese nodule and preservation of Fe isotope composition

715 from seawater.

717 The elemental composition for the nodule determined through bulk and micro-probe

718 measurements, is typical of that reported for deep-sea hydrogenetic manganese nodules (Hein et

719 al., 2013) and indicates that the source of metals to the nodule were from seawater sources, rather

720 than sediments, during the time span we investigated. Fe isotope variations should be controlled

721 by either changes in seawater Fe isotope composition, or by geochemical processes occurring in

722 the nodule. The two main possible causes for fine-scale Fe isotope variability are the diffusion of

723 Fe throughout the nodule and from seawater, and isotopic fractionation during exchange reactions

724 and alteration to more stable phases associated with sorption reactions.

725 Based on a calculated diffusion coefficient for the nodule $\left(<1.10^{-12} \mathrm{~cm}^{2} / \mathrm{yr}\right)$ (Henderson and

726 Burton, 1999), we suggest that diffusion of Fe from seawater to the nodule cannot explain the

727 homogeneous $\delta^{56 / 54} \mathrm{Fe}$ pattern. Our results rule out the effect of mineral alteration as a cause of

728 measurable Fe isotopic fractionation. As discussed above, we did observe changes in the nodule

729 mineralogy as well as variations in Fe contents and Mn/Fe ratios, as shown by $\mu$ XRF and EMPA

730 transects data in Figures 1-3, which could potentially have altered the original distribution of Fe

731 isotopes along the nodule. However, while the Fe minerals in the nodule altered to more stable

732 phases over time, the Fe isotope composition, on a 2-3 $\mathrm{mm}$ sampling scale along the radius of

733 growth, remained constant throughout the nodule (- $0.12 \pm 0.07 \%)$. Despite a range of Fe isotope 
734 fractionation factors that were measured during laboratory experiments involving adsorption

735 reactions and scavenging on Fe-phases (e.g.(Bullen et al., 2001; Johnson et al., 2005; Skulan et

736 al., 2002; Wu et al., 2011)), Horner et al. (2015) report that the isotopic fractionation caused by

737 the precipitation of dissolved seawater Fe (most likely in the form of Fe(III)-ligand) to

738 hydrogenetic ferromanganese crusts is $\Delta^{56 / 54} \mathrm{Fe}=+0.77 \pm 0.06 \%$. If we apply this fractionation

739 factor, $\Delta^{56 / 54} \mathrm{Fe}$ (seawater-nodule $)=\delta^{56 / 54} \mathrm{Fe}($ seawater $)-\delta^{56 / 54} \mathrm{Fe}$ (nodule), to our hydrogenetic

740 nodule, then we obtain a $\delta^{56 / 54} \mathrm{Fe}$ source value of $+0.65 \%$ which is consistent with dissolved $\mathrm{Fe}$

741 dominated by dust dissolution as reported in the Atlantic Ocean (e.g. $+0.70 \pm 0.01 \%$; (Conway

742 and John, 2014)). Finally, implementation of our analytical approach to different type of nodules

743 (e.g. including nodules with a high diagenetic imprint) will help addressing the issue of the

744 influence of the nature of precursor Fe-phases on the fractionation of Fe isotopes during sorption

745 reactions and scavenging.

\section{Conclusions}

Our results provide a framework for addressing the degree to which deep-sea

ferromanganese nodules are archives of past oceanic conditions through trace element uptake and 753 preservation of chemical and isotopic features over time. First, in the Fe mineralogy, we observe

754 a transition from a low abundance of goethite in the "outer matrix" to higher abundance in the

755 "inner matrix" that is consistent with transformation of lepidocrocite- and ferrihydrite-like phases

756 to goethite over time. From these observations, we propose that the incipient Fe "matrix" is

757 composed of poorly ordered ferrihydrite and lepidocrocite phases. The initial trace element

758 uptake signatures should then be determined by the characteristics of the incipient phases and the 759 composition of the seawater at the sediment-water interface. As these phases are buried within

760 the nodule by subsequent mineral growth at the nodule surface, we observe evidence for mineral

761 transformation. Despite mineral transformation to more stable phases, the $\mathrm{Ti}$ and $\mathrm{V}$ coordination

762 chemistry and Fe stable isotope signatures are consistent along the growth radius of the SPG-2

763 nodule. These observations indicate that while the Fe mineral phases within nodules do undergo

764 alteration to more stable phases, the trace element speciation (with $\mathrm{Ti}$ and $\mathrm{V}$ as examples) and $\mathrm{Fe}$

765 isotope composition do not change in response. The primary implication of these findings is that

766 buried layers of nodules are out of contact—geochemically—with surrounding seawater. 
Therefore, we conclude that the Fe minerals in MFNs are indeed faithful recorders of trace

768 elements, at least $\mathrm{Ti}$ and $\mathrm{V}$, over time.

\section{Figure and table captions}

771 Figure 1. Backscatter SEM images showing "outer" and "inner" regions. Red lines and crosses

772 show locations of electron microprobe analyses displayed in Figure 4. The red line in Figure 1b 773 transects an individual botryoidal structure.

775 Figure 2: Ternary diagram of $\mathrm{Fe}, \mathrm{Mn}$ and (Ni+Co) x 10 (adapted from Bonatti et al., 1972) of

776 Electron Microprobe data acquired along a transect through the whole nodule and bulk ICP-AES

777 measurements on the nodule section. The distinction between "inner" and "outer" regions is

778 explained in Table S2 and in the text. This diagram allows to distinguish between three different

779 fields (hydrothermal, hydrogenetic and diagenetic) indicating the predominant origin of the

780 Fe/Mn-rich deposits formation. Selected literature data from Southeast Pacific nodules (green

781 field) (Halbach et al., 1981) and Northeast Pacific (grey field) (Halbach et al. , 1981) are

782 included for comparison.

784 Figure 3. Survey of the sample from "outer" (left) to "inner" regions. Top: Visible-light micrograph of the nodule. Middle: Tricolor-coded map showing Fe (red), Mn (green) and Ni

786 (blue) in a strip extending from the surface of the nodule (left). Bottom: Averages Fe, Mn and

787 Ni counts across the map. Ni counts are multiplied by 10 relative to $\mathrm{Mn}$ and Fe, for clarity. The 788 micrograph and map are to the same field of view as the plot.

790 Figure 4: Plots of Ni/Fe (A), Co/Fe (B), $\mathrm{Zn} / \mathrm{Fe}(\mathrm{C})$ and $\mathrm{Ti} / \mathrm{Fe}(\mathrm{D})$ ratios versus $\mathrm{Mn} / \mathrm{Fe}$ ratio of 791 electron microprobe data acquired along two transects in the nodule "outer" and "inner" regions.

792 Position of the transects in the nodule section are shown in Figure 1. See text for more 793 explanation.

795 Figure. 5. $\mu \mathrm{XRF}$ maps of representative "inner" and "outer" regions showing several elements.

796 Note that the distributions of $\mathrm{V}$ and $\mathrm{Ti}$ almost precisely match that of $\mathrm{Fe}$. $\mathrm{Zn}$ is somewhat 797 enriched in the matrix areas. Brighter pixels correspond to higher concentrations. Scale bars are $798500 \mu \mathrm{m}$. 
Figure 6: Bicolor-coded maps of Ti (a,c) and V (b,d) in red, Fe in blue in "inner" and "outer regions. In map (e), where Fe is shown as red and $\mathrm{Mn}$ as cyan, the Fe-rich "matrix" appears in red and the "botryoidal" material in shades of blue-green. Scale bars are $1 \mathrm{~mm}$.

Figure 7. EXAFS data (thick lines, symbols) and fits (thin lines) for matrix spots and corresponding tricolor maps showing location of spots at which EXAFS data were taken. The fit for the "outer" is a three-shell fit as discussed in text. The fit for the "inner" is a linear combination fit to goethite and feroxyhite. Scale bars are $200 \mu \mathrm{m}$.

Figure 8. Micro-XRD on "outer matrix" spots. Abscissa is $\mathrm{q}=2 \pi / \mathrm{d}\left(\mathrm{nm}^{-1}\right)$. The red and blue curves at top and bottom are simulated powder patterns for lepidocrocite and goethite, respectively. The red curve is flipped vertically to make it easier to trace the peak positions. The numbered peak locations for feroxyhite are from (Drits et al., 1993), classified by intensity. Sharp peaks marked with asterisks match albite.

Figure 9. Tricolor-coded $\mu$ XRF maps showing botryoidal spots on which spectroscopy was performed in "outer" (a) and "inner" (b) regions. Scale bars are $200 \mu \mathrm{m}$ (a) and $800 \mu \mathrm{m}$ (b).

Figure 10. Fit of Inner spot 5 (see bottom panel of Figure 9) to Fe-O, two Fe-Fe shells and goethite. The top panel shows the contributions of each shell (divided by 2). The bottom panel shows the magnitude and imaginary parts of the FT for data and fit.

Figure 11. XANES for Ti in "inner" matrix (average of 3 spots, black) compared with that of ilmenite (red).

Figure 12. V K-XANES spectra for the ITFA end-members found in the nodule (solid black, solid red), $\mathrm{V}(\mathrm{V})$ on 2-line ferrihydrite (dashed black), and $\mathrm{V}(\mathrm{IV})$ on $\delta-\mathrm{MnO}_{2}$ (dashed red). The inset shows the pre-edge region on an expanded scale.

Figure 13. Correlation between fitted fraction of ITFA1 end-member and the ratio of counts in the Fe to Mn XRF channels. Small tricolor (red=Fe, green=Mn, blue=Ni) maps show where points were taken. Maps Inner2 and Outer2 were taken in the same run on the same thin-section; map Inner1 came from a different run and thin section. Map Inner1 is $777 \mu \mathrm{m}$ tall; maps Inner2 and Outer2 are $2000 \mu \mathrm{m}$ tall. 
835 Figure 14. Fits of the ITFA0 (black) and ITFA1 (red) end-members to $\delta$ - $\mathrm{MnO}_{2}$-sorbed V, 2-line

836 ferrihydrite-sorbed $\mathrm{V}$ and $\mathrm{LaCl}_{3} \cdot 7 \mathrm{H} 2 \mathrm{O}$. Data and residuals are shown in points and fits in solid 837 lines.

840 Table 1 . Wet chemical analyses of the nodule section measured by ICP-AES

Table EA1 (Electronic Annex) Be isotopes (a) and calculation of the nodule growth rate (b).

Table EA2 (Electronic Annex). Electron microprobe analyses (in wt \%) of 10 transects through the whole nodule section (from "outer" to "inner" nodule) and elemental ratios.

Table EA3 (Electronic Annex). Electron microprobe analyses (in wt \%) of two micro-transects in the "outer" and "inner" nodule regions and elemental ratios

\section{Acknowledgments}

852 We thank the science team, crew, and Chief Scientist Steven D'Hondt of the KNOX02RR cruise

853 for access to the South Pacific Gyre. We thank Tristan Horner for helpful discussions of the

854 manuscript; Lindsey Briscoe for measuring the XRD pattern of feroxyhite (Characterization

855 Facility, University of Minnesota, which receives partial support from NSF through the MRSEC

856 program); Fred Davis for measuring the elemental composition by electron microprobe (Electron

857 Microprobe Laboratory, University of Minnesota), Shahida Quazi for assistance at ALS BL

858 10.3.2, and Terhuhiko Kashiwabara for discussions and reference spectra for V and La,

859 Emmanuel Ponzevera, Yoan Germain and Celine Liorzou for technical assistance at Ifremer-

860 IUEM, and Purdue University's PRIME Lab for ${ }^{10} \mathrm{Be}$ AMS measurements.. The Advanced Light

861 Source is supported by the Director, Office of Science, Office of Basic Energy Sciences, of the

862 U.S. Department of Energy under Contract No. DE-AC02-05CH11231. OR and BG thank

863 funding sources from ANR-10-LABX-19-01 and Institut Carnot - EDROME.

\section{REFERENCES}

866 Albarède, F. and Beard, B. (2004) Analytical methods for non-traditional isotopes. Reviews in 867 mineralogy and geochemistry 55, 113-152. 
868

Aplin, A.C. and Cronan, D.S. (1985) Ferromanganese oxide deposits from the Central Pacific Ocean, II. Nodules and associated sediments. Geochim. Cosmochim. Acta 49, 437-451. Axelsson, M.D., Rodushkin, I., Ingri, J. and Ohlander, B. (2002) Multielemental analysis of MnFe nodules by ICP-MS: optimisation of analytical method. Analyst 127, 76-82.

Banakar, V.K. and Tarkian, M. (1991) Genesis and growth of internal microstructures of manganese nodules. Indian Journal of Marine Sciences 20, 20-24.

Banerjee, R., Roy, S., Dasgupta, S., Mukhopadhyay, S. and Miura, H. (1999) Petrogenesis of ferromanganese nodules from east of the Chagos Archipelago, Central Indian Basin, Indian Ocean. Marine Geology 157, 145-158.

Baturin, G.N. and Savenko, V.S. (1989) Growth rates of deep- water iron-manganese nodules. Oceanology 29, 334-342.

Beard, B.L., Johnson, C.M., Von Damm, K.L. and Poulson, R.L. (2003) Iron isotope constraints on Fe cycling and mass balance in oxygenated Earth oceans. Geology 31, 629-632.

Bhat, S., Krishnaswami, S., Lal, D., Rama, D. and Somayajulu, B. (1973) Radiometric and trace element studies of ferromanganese nodules, Proc. Symp. Hydrogeochemistry and Biogeochemistry, pp. 443-462.

Birnie, A.C. and Paterson, E. (1991) The mineralogy and morphology of iron and manganese oxides in an imperfectly-drained Scottish soil. Geoderma 50, 219-237.

Brown, G.E., Jr, Henrich, V.E., Casey, W.H., Clark, D.L., Eggleston, C., Felmy, A., Goodman, D.W., Gratzel, M., Maciel, G., McCarthy, M.I., Nealson, K.H., Sverjensky, D.A., Toney, M.F. and Zachara, J.M. (1999) Metal oxide surfaces and their interactions with aqueous solutions and microbial organisms. Chemical Reviews 99, 77-174.

Bullen, T.D., White, A.F., Childs, C.W., Vivit, D.V. and Schulz, M.S. (2001) Demonstration of significant abiotic iron isotope fractionation in nature. Geology 29, 699-702.

Calvert, S.E. and Cronan, D.S. (1978) Geochemistry of oceanic ferromanganese deposits. Philosophical Transactions of the Royal Society London A 290, 43-73.

Carlson, L. and Schwertmann, U. (1980) Natural occurrence of feroxyhite ( $\delta$ '-FeOOH). Clays and Clay Minerals 28, 272-280.

Chmeleff, J., von Blanckenburg, F., Kossert, K. and Jakob, D. (2010) Determination of the ${ }^{10} \mathrm{Be}$ half-life by multicollector ICP-MS and liquid scintillation counting. Nuclear Instruments and Methods in Physics Research Section B: Beam Interactions with Materials and Atoms 268, 192199.

Chu, N.-C., Johnson, C., Beard, B., German, C., Nesbitt, R., Frank, M., Bohn, M., Kubik, P., Usui, A. and Graham, I. (2006) Evidence for hydrothermal venting in Fe isotope compositions of the deep Pacific Ocean through time. Earth and Planetary Science Letters 245, 202-217. Chukhrov, F., Zvyagin, B., Gorshkov, A., Yermilova, L., Korovushkin, V., Rudnitskaya, Y.S. and Yakubovskaya, N.Y. (1977) Feroxyhyte, a new modification of FeOOH. International Geology Review 19, 873-890.

Conway, T.M. and John, S.G. (2014) Quantification of dissolved iron sources to the North Atlantic Ocean. Nature 511, 212-215.

Cornell, R.M., R, G. and Schneider, W. (1992) The effect of nickel on the conversion of amorphous iron(III) hydroxide into more crystalline iron oxides in alkaline media. J. Chem. Tech. Biotechnol. 53, 73-79.

Cornell, R.M. and Schwertmann, U. (2003) The Iron Oxides: Structure, properties, reactions, occurrences and uses, Second, completely revised and extended ed. Wiley-VCH, Darmstadt, Germany.

Cronan, D.S. (1975) Manganese nodules and other ferromangese oxide deposits from Atlantic Ocean. Journal of Geophysical Research-Oceans and Atmospheres 80, 3831-3837.

D'Hondt, S., Spivack, A.J., Pockalny, R., Ferdelman, T.G., Fischer, J.P., Kallmeyer, J., Abrams, L.J., Smith, D.C., Graham, D., Hasiuk, F., Schrum, H. and Stancin, A.M. (2009) Subseafloor 

sedimentary life in the South Pacific Gyre. Proceedings of the National Academy of Sciences 106, 11651-11656.

Dauphas, N. and Rouxel, O. (2006) Mass spectrometry and natural variations of iron isotopes. Mass Spectrometry Reviews 25, 515-550.

de Lange, G.J., van Os, B. and Poorter, R. (1992) Geochemical composition and inferred accretion rates of sediments and manganese nodules from a submarine hill in the Madeira Abyssal Plain, eastern North Atlantic. Marine Geology 109, 171-194.

Dideriksen, K., Baker, J.A. and Stipp, S.L.S. (2006) Iron isotopes in natural carbonate minerals determined by MC-ICP-MS with a Fe-58-Fe-54 double spike. Geochimica Et Cosmochimica Acta 70, 118-132.

Drits, V., Sakharov, B. and Manceau, A. (1993) Structure of feroxyhite as determined by simulation of X-ray diffraction curves. Clay Minerals 28, 209-209.

Dublet, G., Juillot, F., Morin, G., Fritsch, E., Fandeur, D. and Brown, G.E. (2015) Goethite aging explains Ni depletion in upper units of ultramafic lateritic ores from New Caledonia. Geochim. Cosmochim. Acta 160, 1-15.

Dymond, J., Lyle, M.W., Finney, B., Piper, D.Z., Murphy, K., Conard, R. and Pisias, N. (1984)

Ferromanganese nodules from MANOP Sites H, S, and R - Control of mineralogical and chemical composition by multiple accretionary processes. Geochim. Cosmochim. Acta 48, 931949.

Ebert, K., Willenbring, J., Norton, K.P., Hall, A. and Hättestrand, C. (2012) Meteoric ${ }^{10}$ Be concentrations from saprolite and till in northern Sweden: Implications for glacial erosion and age. Quaternary Geochronology 12, 11-22.

Eickhoff, M., Obst, M., Schröder, C., Hitchcock, A.P., Tyliszczak, T., Martinez, R.E., Robbins, L.J., Konhauser, K.O. and Kappler, A. (2014) Nickel partitioning in biogenic and abiogenic ferrihydrite: The influence of silica and implications for ancient environments. Geochim. Cosmochim. Acta 140, 65-79.

Elderfield, H., Hawkesworth, C.J., Greaves, M.J. and Calvert, S.E. (1981) Rare-earth element zonation in Pacific ferromanganese nodules. Geochim. Cosmochim. Acta 45, 1231-1234. Frierdich, A.J. and Catalano, J.G. (2012) Controls on Fe(II)-activated trace element release from goethite and hematite. Environ. Sci. Technol. 46, 1519-1526.

Frierdich, A.J., Luo, Y. and Catalano, J.G. (2011) Trace element cycling through iron oxide minerals during redox-driven dynamic recrystallization. Geology 39, 1083-1086.

Gradstein, F. and Ogg, J. (2002) Future directions in stratigraphy. Episodes 25, 203-208. Graham, I., Carter, R., Ditchburn, R. and Zondervan, A. (2004) Chronostratigraphy of ODP 181, Site 1121 sediment core (Southwest Pacific Ocean), using ${ }^{10} \mathrm{Be} /{ }^{9} \mathrm{Be}$ dating of entrapped ferromanganese nodules. Marine geology 205, 227-247.

Halbach, P. and Puteanus, D. (1984) The influence of the carbonate dissolution rate on the growth and composition of Co-rich ferromanganese crusts from Central Pacific seamount areas. Earth and Planetary Science Letters 68, 73-87.

Halbach, P., Scherhag, C., Hebisch, U. and Marchig, V. (1981) Geochemical and mineralogical control of different genetic types of deep-sea nodules from the Pacific Ocean. Mineralium deposita 16, 59-84.

Hammersley, A. (1997) FIT2D: an introduction and overview. European Synchrotron Radiation Facility Internal Report ESRF97HA02T.

Heggie, D., Kahn, D. and Fischer, K. (1986) Trace metals in metalliferous sediments, MANOP Site M: interfacial pore water profiles. Earth and Planetary Science Letters 80, 106-116. Hein, J.R., Koschinsky, A. and Halliday, A.N. (2003) Global occurrence of tellurium-rich ferromanganese crusts and a model for the enrichment of tellurium. Geochim. Cosmochim. Acta 67, 1117-1127. 
Hein, J.R., Mizell, K., Koschinsky, A. and Conrad, T.A. (2013) Deep-ocean mineral deposits as a

1001

1002

1003

1004

1005

1006

1007

1008

1009

1010

1011

1012

1013

1014

1015

1016

source of critical metals for high- and green-technology applications: Comparison with landbased resources. Ore Geology Reviews 51, 1-14.

Henderson, G.M. and Burton, K.W. (1999) Using $\left({ }^{234} U /{ }^{238} U\right)$ to assess diffusion rates of isotope tracers in ferromanganese crusts. Earth and Planetary Science Letters 170, 169-179.

Horner, T.J., Williams, H.M., Hein, J.R., Saito, M.A., Burton, K.W., Halliday, A.N. and Nielsen, S.G. (2015) Persistence of deeply sourced iron in the Pacific Ocean. Proceedings of the National Academy of Sciences, 201420188.

Jahnke, R.A. (1996) The global ocean flux of particulate organic carbon: Areal distribution and magnitude. Global biogeochemical cycles 10, 71-88.

John, S.G., Mendez, J., Moffett, J. and Adkins, J. (2012) The flux of iron and iron isotopes from San Pedro Basin sediments. Geochim. Cosmochim. Acta 93, 14-29.

Johnson, C.M., Roden, E.E., Welch, S.A. and Beard, B.L. (2005) Experimental constraints on Fe isotope fractionation during magnetite and Fe carbonate formation coupled to dissimilatory hydrous ferric oxide reduction. Geochim. Cosmochim. Acta 69, 963-993.

Klinkhammer, G., Heggie, D.T. and Graham, D.W. (1982) Metal diagenesis in oxic marinesediments. Earth and Planetary Science Letters 61, 211-219.

Korschinek, G., Bergmaier, A., Faestermann, T., Gerstmann, U., Knie, K., Rugel, G., Wallner, A., Dillmann, I., Dollinger, G. and Von Gostomski, C.L. (2010) A new value for the half-life of

${ }^{10}$ Be by Heavy-Ion Elastic Recoil Detection and liquid scintillation counting. Nuclear Instruments and Methods in Physics Research Section B: Beam Interactions with Materials and Atoms 268, 187-191.

Koschinsky, A. and Halbach, P. (1995) Sequential leaching of marine ferromanganese precipitates: Genetic implications. Geochim. Cosmochim. Acta 59, 5113-5132.

Koschinsky, A. and Hein, J.R. (2003) Uptake of elements from seawater by ferromanganese crusts: solid-phase associations and seawater speciation. Marine geology 198, 331-351.

Koschinsky, A., Stascheit, A., Bau, M. and Halbach, P. (1997) Effects of phosphatization on the geochemical and mineralogical composition of marine ferromanganese crusts. Geochim. Cosmochim. Acta 61, 4079-4094.

Larson, R.L., Pockalny, R.A., Viso, R.F., Erba, E., Abrams, L.J., Luyendyk, B.P., Stock, J.M. and Clayton, R.W. (2002) Mid-Cretaceous tectonic evolution of the Tongareva triple junction in the southwestern Pacific Basin. Geology 30, 67-70.

Latta, D.E., Gorski, C.A. and Scherer, M.M. (2012) Influence of $\mathrm{Fe}^{2+}$-catalyzed iron oxide recrystallization on metal cycling. Biochemical Society Transations 40, 1191-1197.

Levasseur, S., Frank, M., Hein, J. and Halliday, A. (2004) The global variation in the iron isotope composition of marine hydrogenetic ferromanganese deposits: implications for seawater chemistry? Earth and Planetary Science Letters 224, 91-105.

Lu, B., Guo, H., Li, P., Liu, H., Wei, Y. and Hou, D. (2011) Comparison study on transformation of iron oxyhydroxides: Based on theoretical and experimental data. Journal of Solid State Chemistry 184, 2139-2144.

Manceau, A., Lanson, M. and Takahashi, Y. (2014) Mineralogy and crystal chemistry of Mn, Fe, $\mathrm{Co}, \mathrm{Ni}$, and $\mathrm{Cu}$ in a deep-sea Pacific polymetallic nodule. Am. Mineral. 99, 2068-2083. Manceau, A., Marcus, M.A. and Tamura, N. (2002) Quantitative speciation of heavy metals in soils and sediments by synchrotron X-ray techniques, in: Fenter, P.A., Rivers, M.L., Sturchio, N.C., Sutton, S.R. (Eds.), Applications of Synchrotron Radiation in Low-Temperature Geochemistry and Environmental Science. Mineralogical Society of America, Washington, DC, pp. 341-428.

Marcus, M.A., MacDowell, A.A., Celestre, R., Manceau, A., Miller, T., Padmore, H.A. and Sublett, R.E. (2004a) Beamline 10.3.2 at ALS: a hard X-ray microprobe for environmental and materials sciences. J. Synchrotron Radiation 11, 239-247. 
Marcus, M.A., Manceau, A. and Kersten, M. (2004b) Mn, Fe, Zn and As speciation in a fast-

1018

1019 growing ferromanganese marine nodule. Geochim. Cosmochim. Acta 68, 3125-3136.

1020

1021

1022

1023

1024

1025

1026

1027

1028 Marcus, M.A., Westphal, A.J. and Fakra, S.C. (2008) Classification of Fe-bearing species from K-edge XANES data using two-parameter correlation plots. J. Synchrotron Radiation 15, 463468.

Martin-Barajas, A., Lallier-Verges, E. and Leclaire, L. (1991) Characteristics of manganese nodules from the Central Indian Basin: Relationship with the sedimentary environment. Marine Geology 101, 249-265.

Martin, J.H. and Fitzwater, S. (1988) Iron deficiency limits phytoplankton growth in the northeast Pacific subarctic. Nature 331, 947-975.

McKenzie, R. (1971) The synthesis of birnessite, cryptomelane, and some other oxides and hydroxides of manganese. Mineralogical Magazine 38, 493-502.

1029

Morford, J.L. and Emerson, S. (1999) The geochemistry of redox sensitive trace metals in

1030 sediments. Geochim. Cosmochim. Acta 63, 1735-1750.

1031

Murad, E. and Schwertmann, U. (1988) Iron oxide mineralogy of some deep-sea ferromanganese

1032 crusts. Am. Mineral. 73, 1395-1400.

1033 Navrotsky, A., Mazeina, L. and Majzlan, J. (2008) Size-driven structural and thermodynamic

1034 complexity in iron oxides. Science 319, 1635-1638.

1035 Newville, M. (2001) IFEFFIT: interactive XAFS analysis and FEFF fitting. J. Synchrotron

1036 Radiation 8, 322-324.

1037 Nicholson, K. and Eley, M. (1997) Geochemistry of manganese oxides: metal adsorption in

1038 freshwater and marine environments, in: Nicholson, K., Hein, J.R., Bühn, B., Dasgupta, S. (Eds.),

1039 Manganese Mineralization: Geochemistry and Mineralogy of Terrestrial and Marine Deposits.

1040 Geological Society Special Publication No. 119. The Geological Society, London, pp. 309-326.

1041 Peacock, C.L. (2009) Physiochemical controls on the crystal-chemistry of Ni in birnessite:

1042 Genetic implications for ferromanganese precipitates. Geochim Cosmochim Acta 73, 3568-3578.

1043 Radic, A., Lacan, F. and Murray, J.W. (2011) Iron isotopes in the seawater of the equatorial

1044 Pacific Ocean: new constraints for the oceanic iron cycle. Earth and Planetary Science Letters

1045 306, 1-10.

1046 Raiswell, R. and Canfield, D.E. (2012) The iron biogeochemical cycle past and present.

1047 Geochemical Perspectives 1, 1-2.

1048

1049

1050

1051

1052

1053

1054

1055

1056

1057

1058

1059

1060

1061

1062

1063

1064

Ravel, B. and Newville, M. (2005) ATHENA, ARTEMIS, HEPHAESTUS: data analysis for Xray absorption spectroscopy using IFEFFIT. J. Synchrotron Radiation 12, 537-541.

Rouxel, O., Shanks III, W.C., Bach, W. and Edwards, K.J. (2008) Integrated Fe-and S-isotope study of seafloor hydrothermal vents at East Pacific Rise 9-10 N. Chemical Geology 252, 214227.

Rouxel, O.J., Bekker, A. and Edwards, K.J. (2005) Iron isotope constraints on the Archean and Paleoproterozoic ocean redox state. Science 307, 1088-1091.

Sawlan, J.J. and Murray, J.W. (1983) Trace-metal remobilization in the interstitial waters of red clay and hemipelagic marine-sediments. Earth and Planetary Science Letters 64, 213-230.

Scholz, F., Severmann, S., McManus, J., Noffke, A., Lomnitz, U. and Hensen, C. (2014) On the isotope composition of reactive iron in marine sediments: Redox shuttle versus early diagenesis. Chemical Geology 389, 48-59.

Schwertman, U. and Cornell, R. (1991) Iron Oxides in the Laboratory Preparation and Characterization. VCH Publishers.

1065 Segl, M., Mangini, A., Beer, J., Bonani, G., Suter, M. and Wölfli, W. (1989) Growth rate

1066 variations of manganese nodules and crusts induced by paleoceanographic events.

1067 Paleoceanography 4, 511-530. 
1068

1069

1070

1071

1072

1073

1074

1075

1076

1077

1078

1079

1080

1081

1082

1083

1084

1085

1086

1087

1088

1089

1090

1091

1092

1093

1094

1095

1096

1097

1098

1099

1100

1101

1102

1103

1104

1105

1106

1107

1108

1109

1110

1111

1112

1113

1114

Severmann, S., McManus, J., Berelson, W.M. and Hammond, D.E. (2010) The continental shelf benthic iron flux and its isotope composition. Geochim. Cosmochim. Acta 74, 3984-4004. Skulan, J.L., Beard, B.L. and Johnson, C.M. (2002) Kinetic and equilibrium Fe isotope fractionation between aqueous Fe (III) and hematite. Geochim. Cosmochim. Acta 66, 2995-3015. Somayajulu, B. (2000) Growth rates of oceanic manganese nodules: implications to their genesis, palaeo-earth environment and resource potential. Current Science 78, 300-308.

Takahashi, Y., Manceau, A., Geoffroy, N., Marcus, M.A. and Usui, A. (2007) Chemical and structural control of the partitioning of $\mathrm{Co}, \mathrm{Ce}$, and $\mathrm{Pb}$ in marine ferromanganese oxides. Geochim. Cosmochim. Acta 71, 984-1008.

Takahashi, Y., Shimizu, H., Kagi, H., Yoshida, H., Usui, A. and Nomura, M. (2000) A new method for the determination of $\mathrm{Ce} \mathrm{e}^{\mathrm{III}} / \mathrm{Ce}^{\mathrm{IV}}$ ratios in geological materials; application for weathering, sedimentary and diagenetic processes. Earth and Planetary Science Letters 182, 201 207.

Tanaka, T., Nishimura, Y., Kawasaki, S.-i., Funabiki, T. and Yoshida, S. (1987) X-Ray absorption spectroscopy (EXAFS/XANES) evidence for the preferential formation of isolated $\mathrm{VO}_{4}$ species on highly photoactive $\mathrm{V}_{2} \mathrm{O}_{5} / \mathrm{SiO}_{2}$ catalysts. Journal of the Chemical Society, Chemical Communications, 506-508.

Toner, B.M., Berquo, T.S., Michel, F.M., Sorensen, J.V., Templeton, A.S. and Edwards, K.J. (2012) Mineralogy of iron microbial mats from Loihi Seamount. Frontiers in Microbiological Chemistry 3, 1-18.

Toner, B.M., Santelli, C.M., Marcus, M.A., Wirth, R., Chan, C.S., McCollom, T.M., Bach, W. and Edwards, K.J. (2009) Biogenic iron oxyhydroxide formation at Mid-Ocean Ridge hydrothermal vents: Juan de Fuca Ridge. Geochim. Cosmochim. Acta 73, 388-403. Verlaan, P.A., Cronan, D.S. and Morgan, C.L. (2004) A comparative analysis of compositional variations in and between marine ferromanganese nodules and crusts in the South Pacific and their environmental controls. Progress in Oceanography 63, 125-158.

Villalobos, M., Toner, B., Bargar, J. and Sposito, G. (2003) Characterization of the manganese oxide produced by Pseudomonas putida strain MnB1. Geochim. Cosmochim. Acta 67, 26492662.

Wang, X., Schloßmacher, U., Wiens, M., Schröder, H.C. and Müller, W.E. (2009) Biogenic origin of polymetallic nodules from the Clarion-Clipperton zone in the Eastern Pacific Ocean: electron microscopic and EDX evidence. Marine Biotechnology 11, 99-108.

Willenbring, J.K. and von Blanckenburg, F. (2010a) Long-term stability of global erosion rates and weathering during late-Cenozoic cooling. Nature 465, 211-214.

Willenbring, J.K. and von Blanckenburg, F. (2010d) Meteoric cosmogenic Beryllium-10 adsorbed to river sediment and soil: Applications for Earth-surface dynamics. Earth-Science Reviews 98, 105-122.

Wong, J., Lytle, F., Messmer, R. and Maylotte, D. (1984) K-edge absorption spectra of selected vanadium compounds. Physical Review B 30, 5596.

Wu, L., Beard, B.L., Roden, E.E. and Johnson, C.M. (2011) Stable iron isotope fractionation between aqueous Fe (II) and hydrous ferric oxide. Environ. Sci. Technol. 45, 1847-1852.

Yoshikawa, K. (1991) The relationship between manganese minerals and metallic elements in deep-sea manganese nodules. Marine Geology 101, 267-286.

Zhu, X.K., O'Nions, R.K., Guo, Y.L. and Reynolds, B.C. (2000) Secular variation of iron isotopes in North Atlantic Deep Water. Science 287, 2000-2002. 


\begin{tabular}{|c|c|c|c|c|c|c|c|c|c|c|c|c|c|c|c|c|c|c|c|c|c|}
\hline Nodule section \# & $\begin{array}{l}\text { Distance from } \\
\text { nodule } \\
\text { surface }(\mathrm{mm})^{\star *}\end{array}$ & $\mathrm{Al} / \mathrm{Fe}$ & $\mathrm{Ba} / \mathrm{Fe}$ & $\mathrm{Ca} / \mathrm{Fe}$ & $\mathrm{Ce} / \mathrm{Fe}$ & $\mathrm{Co} / \mathrm{Fe}$ & $\mathrm{Cu} / \mathrm{Fe}$ & $\mathrm{K} / \mathrm{Fe}$ & $\mathrm{La} / \mathrm{Fe}$ & $\mathrm{Mg} / \mathrm{Fe}$ & $\mathrm{Mn} / \mathrm{Fe}$ & $\mathrm{Mo} / \mathrm{Fe}$ & $\mathrm{Na} / \mathrm{Fe}$ & $\mathrm{Ni} / \mathrm{Fe}$ & $\mathrm{P} / \mathrm{Fe}$ & $\mathrm{Sr} / \mathrm{Fe}$ & $\mathrm{Ti} / \mathrm{Fe}$ & $\mathrm{Zn} / \mathrm{Fe}$ & $\mathrm{Cu} / \mathrm{Ni}$ & ${ }^{56 / 54} \mathrm{Fe}_{\mathrm{IRMM}}$ & ${ }_{1}, 2 s d^{* * *}$ \\
\hline N1 (Outer) & 3 & 0.184 & 0.0085 & 0.119 & 0.0114 & 0.035 & 0.0096 & 0.047 & 0.0015 & 0.0843 & 1.14 & 0.0019 & 0.123 & 0.0217 & 0.017 & 0.0064 & 0.106 & 0.0036 & 0.45 & -0.16 & 0.09 \\
\hline N2 & 6 & 0.165 & 0.0081 & 0.109 & 0.0093 & 0.030 & 0.0076 & 0.040 & 0.0014 & 0.0634 & $4 \quad 0.93$ & 0.0016 & 0.095 & 0.0138 & 0.016 & 0.0057 & 0.105 & 0.0030 & 0.55 & -0.09 & 0.09 \\
\hline N3 & 8 & 0.214 & 0.0078 & 0.122 & 0.0096 & 0.034 & 0.0089 & 0.054 & 0.0015 & 0.0763 & 31.04 & 0.0018 & 0.107 & 0.0184 & 0.019 & 0.0060 & 0.104 & 0.0035 & 0.48 & -0.17 & 0.09 \\
\hline N4 & 10 & 0.191 & 0.0080 & 0.150 & 0.0095 & 0.031 & 0.0095 & 0.040 & 0.0015 & 0.0714 & 41.10 & 0.0018 & 0.106 & 0.0215 & 0.022 & 0.0060 & 0.095 & 0.0038 & 0.44 & -0.14 & 0.09 \\
\hline N5 & 12.5 & 0.199 & 0.0083 & 0.150 & 0.0104 & 0.034 & 0.0094 & 0.032 & 0.0014 & 0.0747 & $7 \quad 1.25$ & 0.0022 & 0.115 & 0.0241 & 0.016 & 0.0066 & 0.087 & 0.0039 & 0.39 & -0.07 & 0.09 \\
\hline N6 & 13.5 & 0.215 & 0.0077 & 0.141 & 0.0096 & 0.028 & 0.0084 & 0.032 & 0.0013 & 0.0677 & $7 \quad 1.04$ & 0.0019 & 0.099 & 0.0182 & 0.016 & 0.0060 & 0.079 & 0.0037 & 0.46 & -0.10 & 0.09 \\
\hline N7 & 14.5 & 0.227 & 0.0072 & 0.126 & 0.0089 & 0.027 & 0.0084 & 0.037 & 0.0011 & 0.0672 & 21.02 & 0.0020 & 0.103 & 0.0169 & 0.015 & 0.0056 & 0.071 & 0.0038 & 0.50 & -0.16 & 0.09 \\
\hline N8 & 16 & 0.193 & 0.0076 & 0.112 & 0.0100 & 0.031 & 0.0085 & 0.038 & 0.0012 & 0.0688 & 31.02 & 0.0021 & 0.098 & 0.0179 & 0.015 & 0.0058 & 0.076 & 0.0040 & 0.48 & & 0.09 \\
\hline N9 & 18 & 0.188 & 0.0071 & 0.110 & 0.0111 & 0.034 & 0.0082 & 0.033 & 0.0012 & 0.0724 & 41.02 & 0.0022 & 0.092 & 0.0183 & 0.016 & 0.0056 & 0.083 & 0.0040 & 0.45 & -0.08 & 0.09 \\
\hline N10 (Inner) & 19.5 & 0.160 & 0.0073 & 0.099 & 0.0133 & 0.026 & 0.0083 & 0.022 & 0.0012 & 0.0682 & 0.92 & 0.0022 & 0.084 & 0.0178 & 0.017 & 0.0055 & 0.075 & 0.0043 & 0.46 & -0.11 & 0.09 \\
\hline USGS Nod-P-1 & & 0.379 & 0.0448 & 0.395 & 0.0064 & 0.041 & 0.2113 & 0.193 & 0.0021 & 0.3360 & 5.10 & 0.0106 & 0.304 & 0.2504 & 0.027 & 0.0114 & 0.052 & 0.0306 & 0.84 & -0.49 & 0.07 \\
\hline USGS Nod-A-1 & - & 0.197 & 0.0140 & 1.129 & 0.0079 & 0.031 & 0.0103 & 0.048 & 0.0013 & 0.2647 & $7 \quad 1.73$ & 0.0035 & 0.081 & 0.0634 & 0.041 & 0.0145 & 0.033 & 0.0059 & 0.16 & -0.40 & 0.09 \\
\hline
\end{tabular}

USGS Nod-A-1

of element per gram of $\mathrm{Fe}$ (i.e. Element/Fe ratios).

** Distance from outer nodule is reported as the distance from the top surface of the nodule.

${ }^{\star * \star} 2$ sd was dtermined on replicate measurements of the Fe isotopic standard IRMM-14. See text for explanations. 

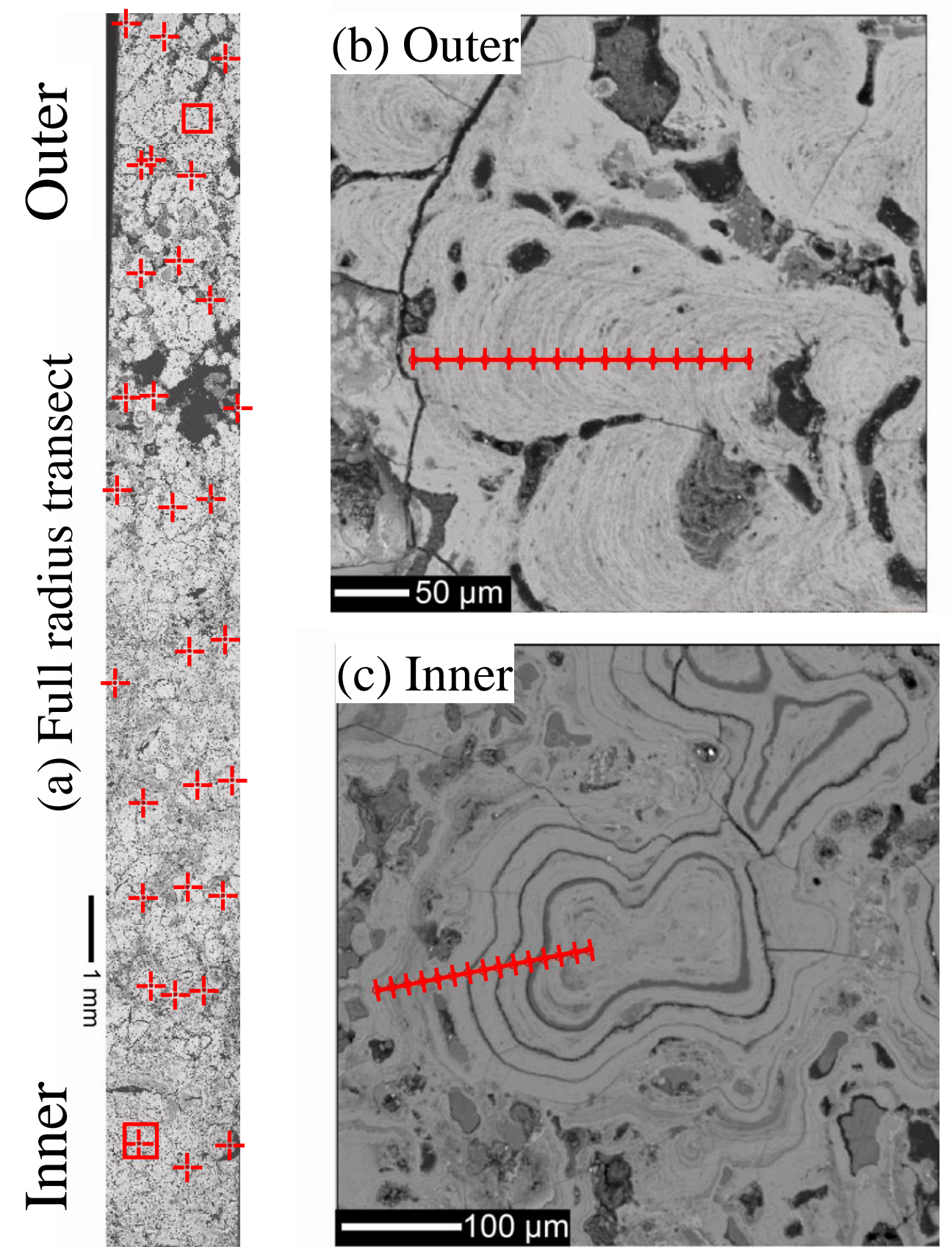


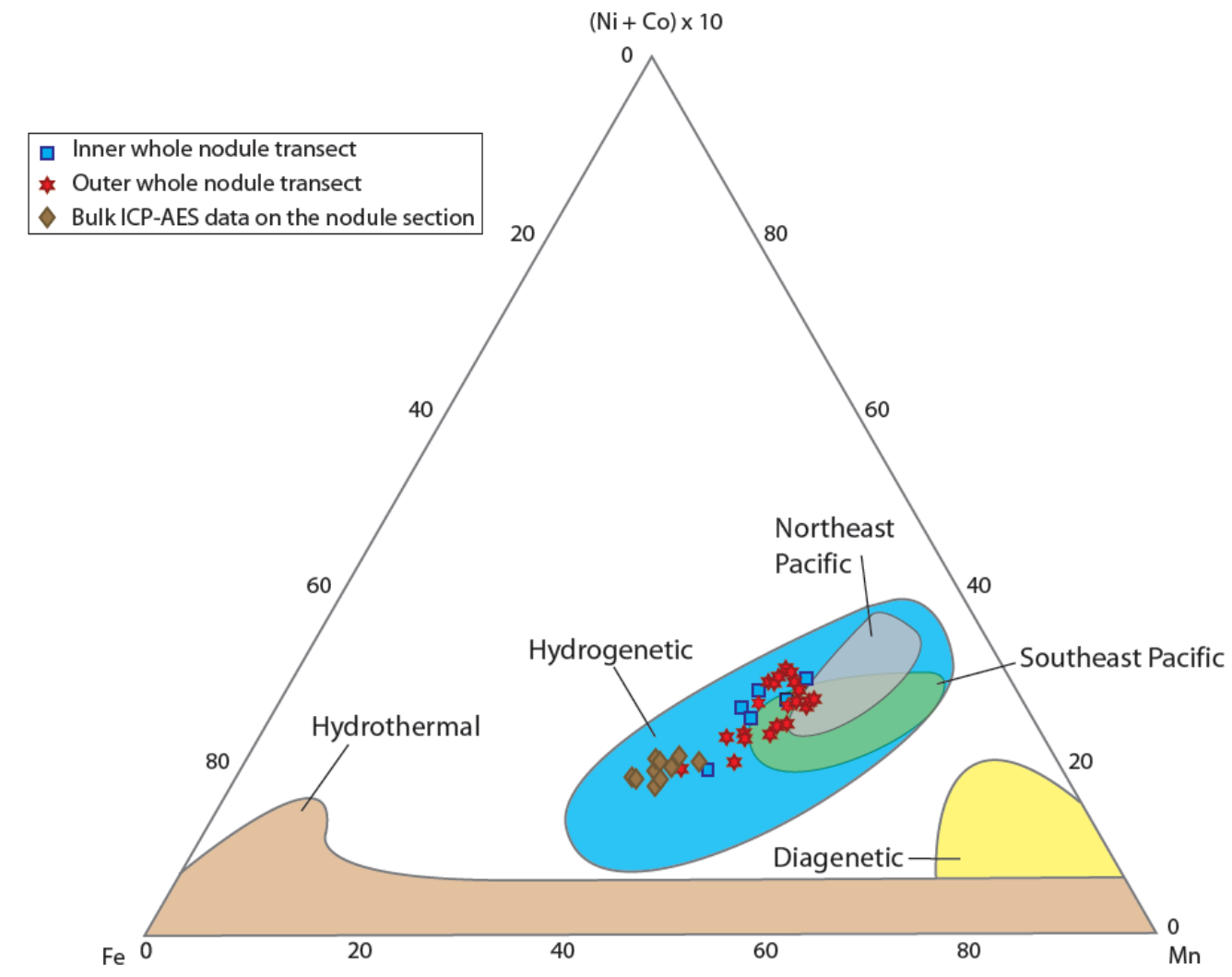




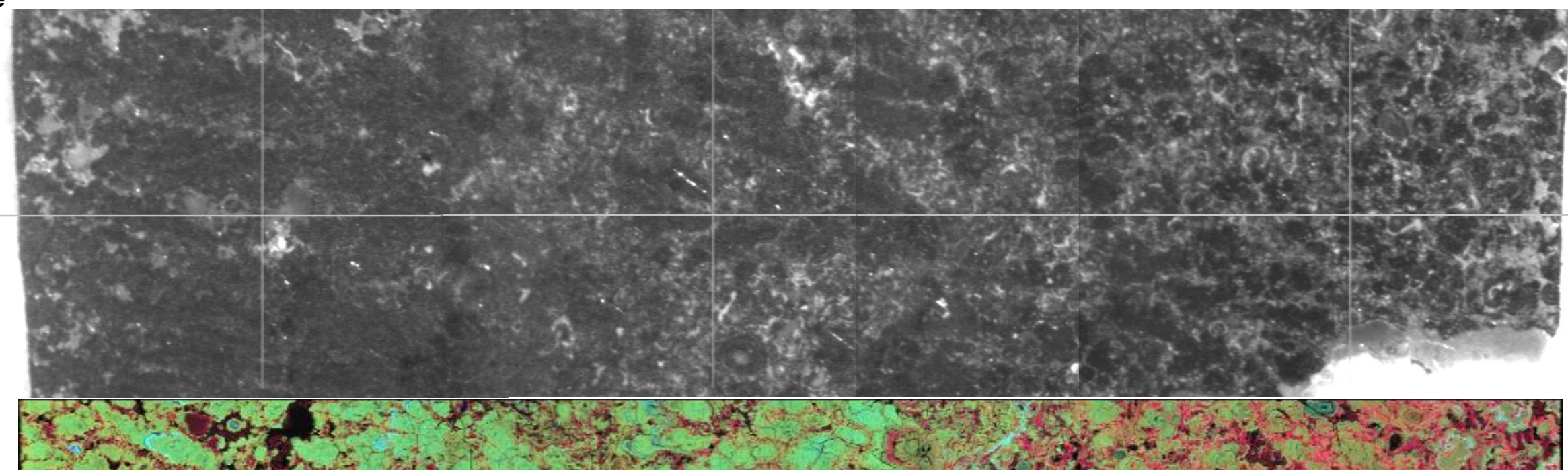

Fe

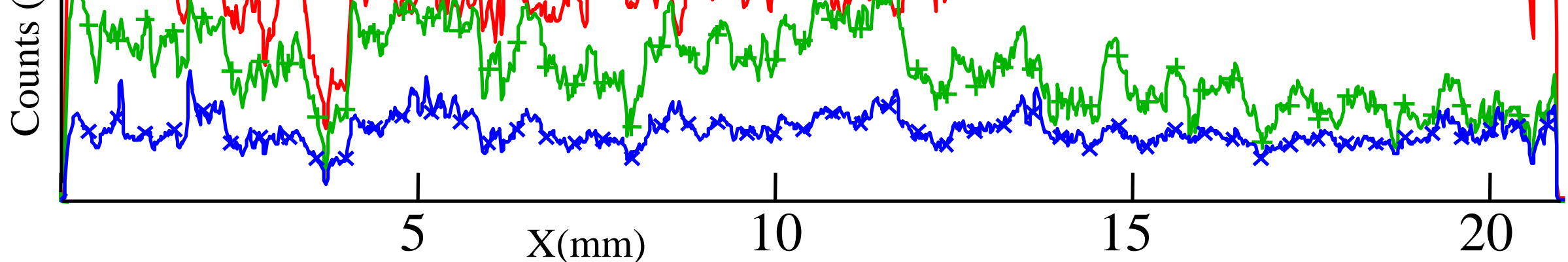

Outer

Inner 

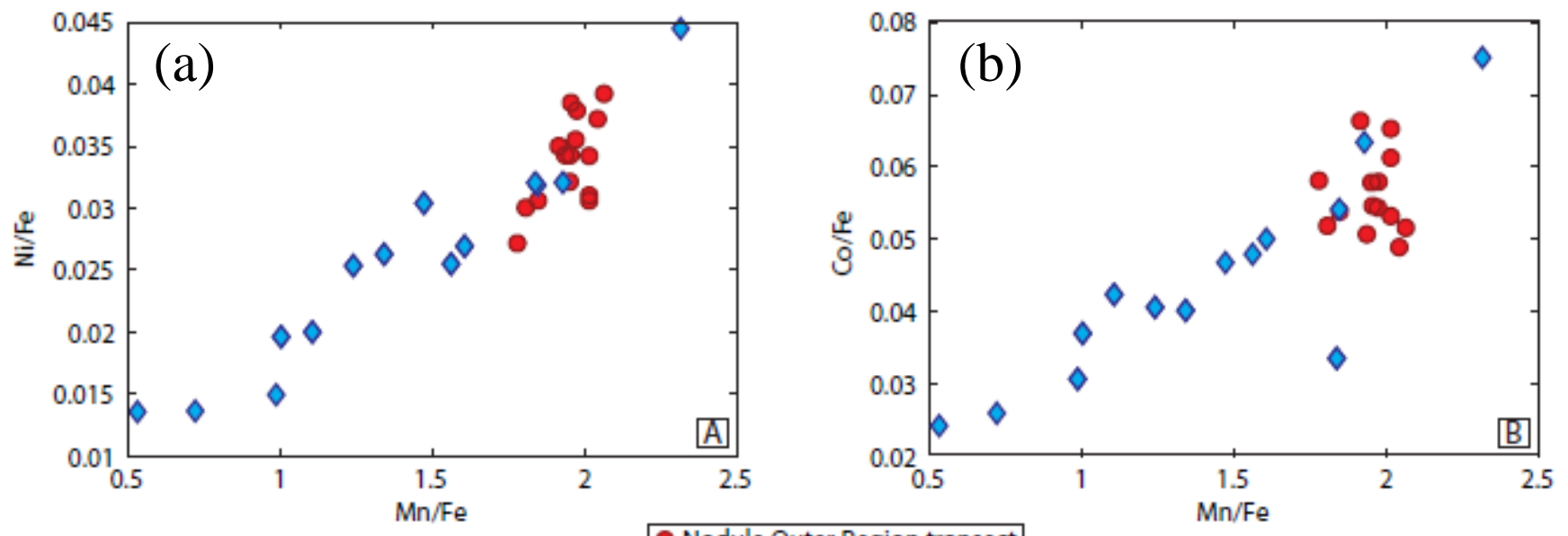

- Nodule Outer Region transect

$\Delta$ Nodule Inner Region transect
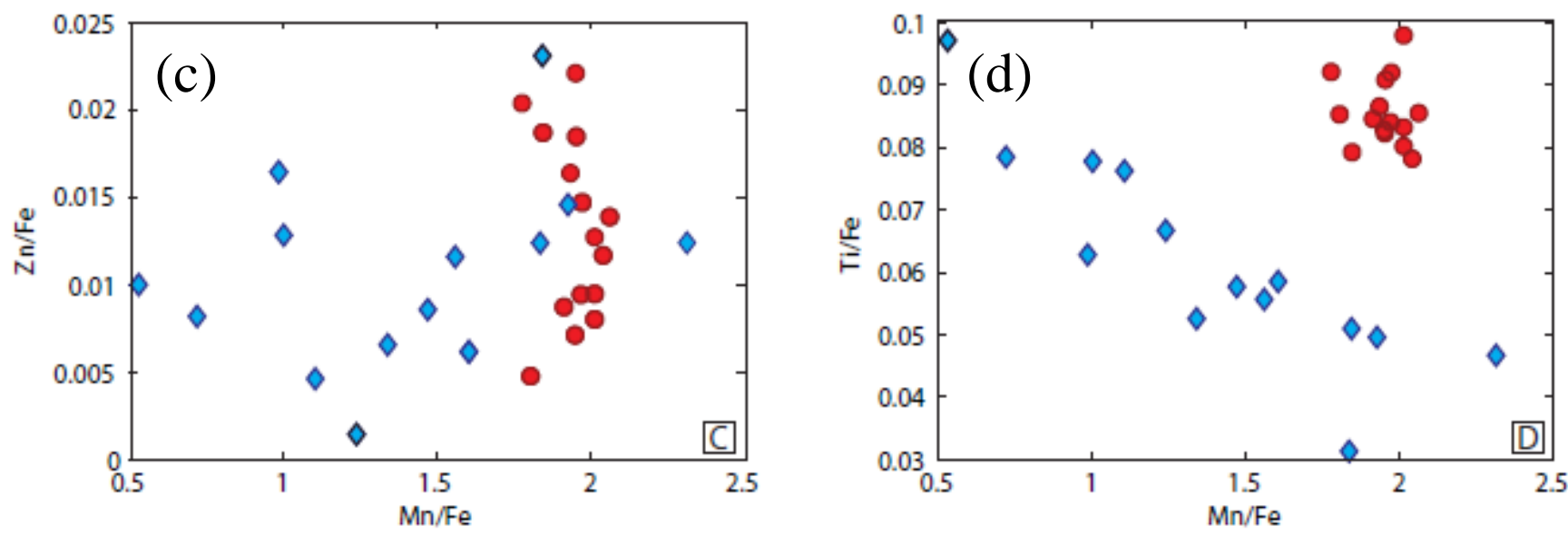
Inner
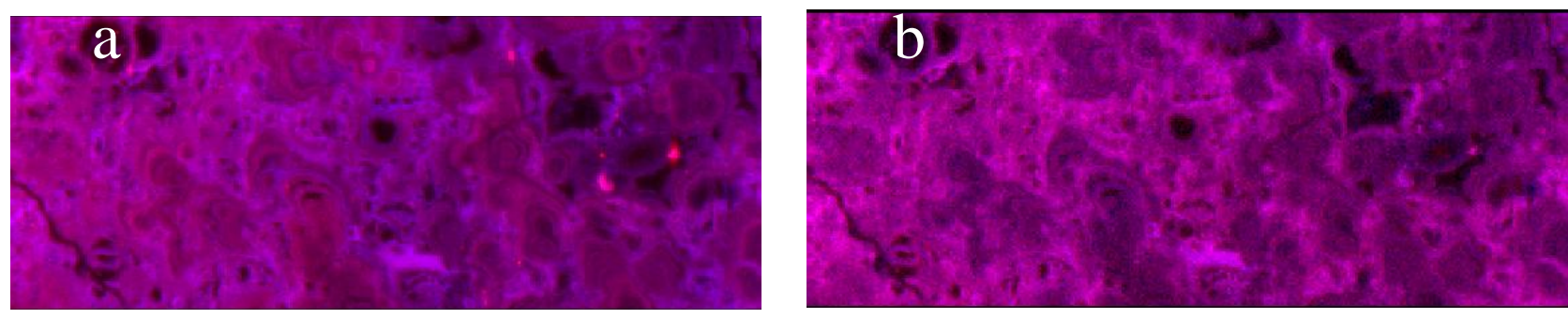

Outer

TiFe
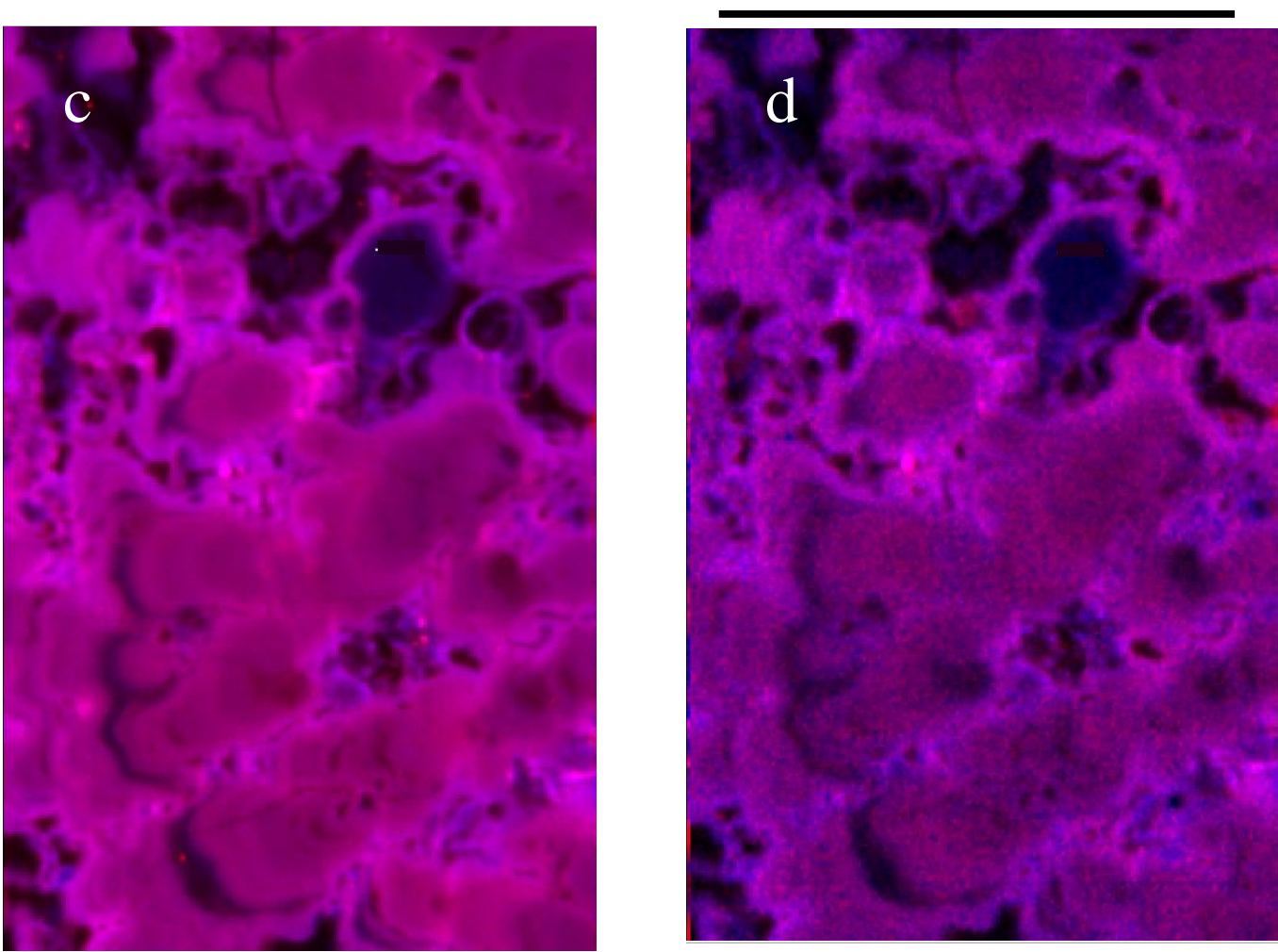

FeMn

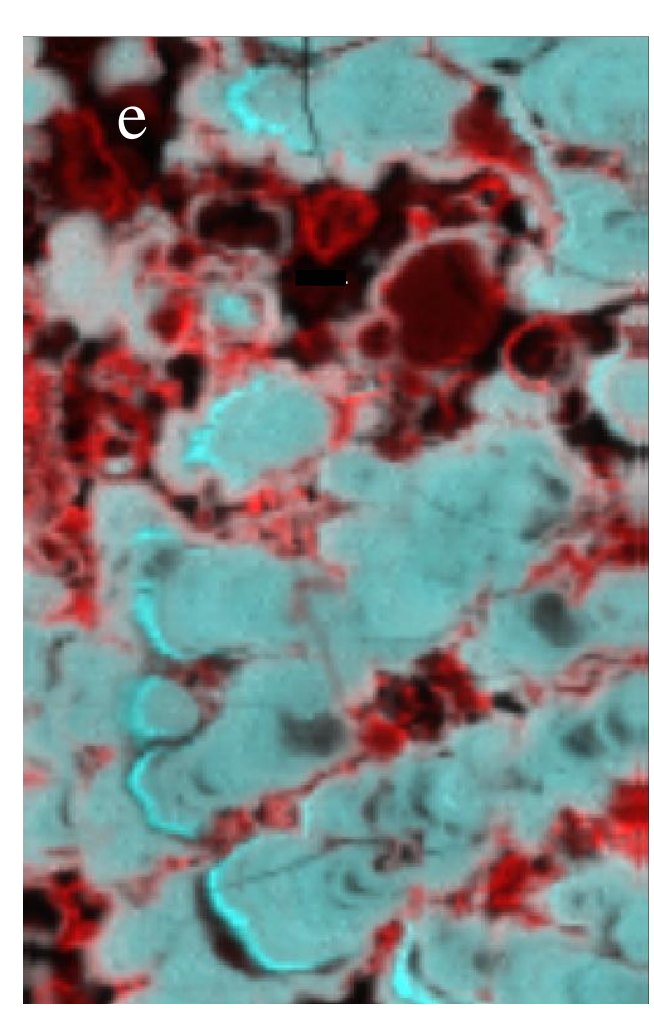

VFe 


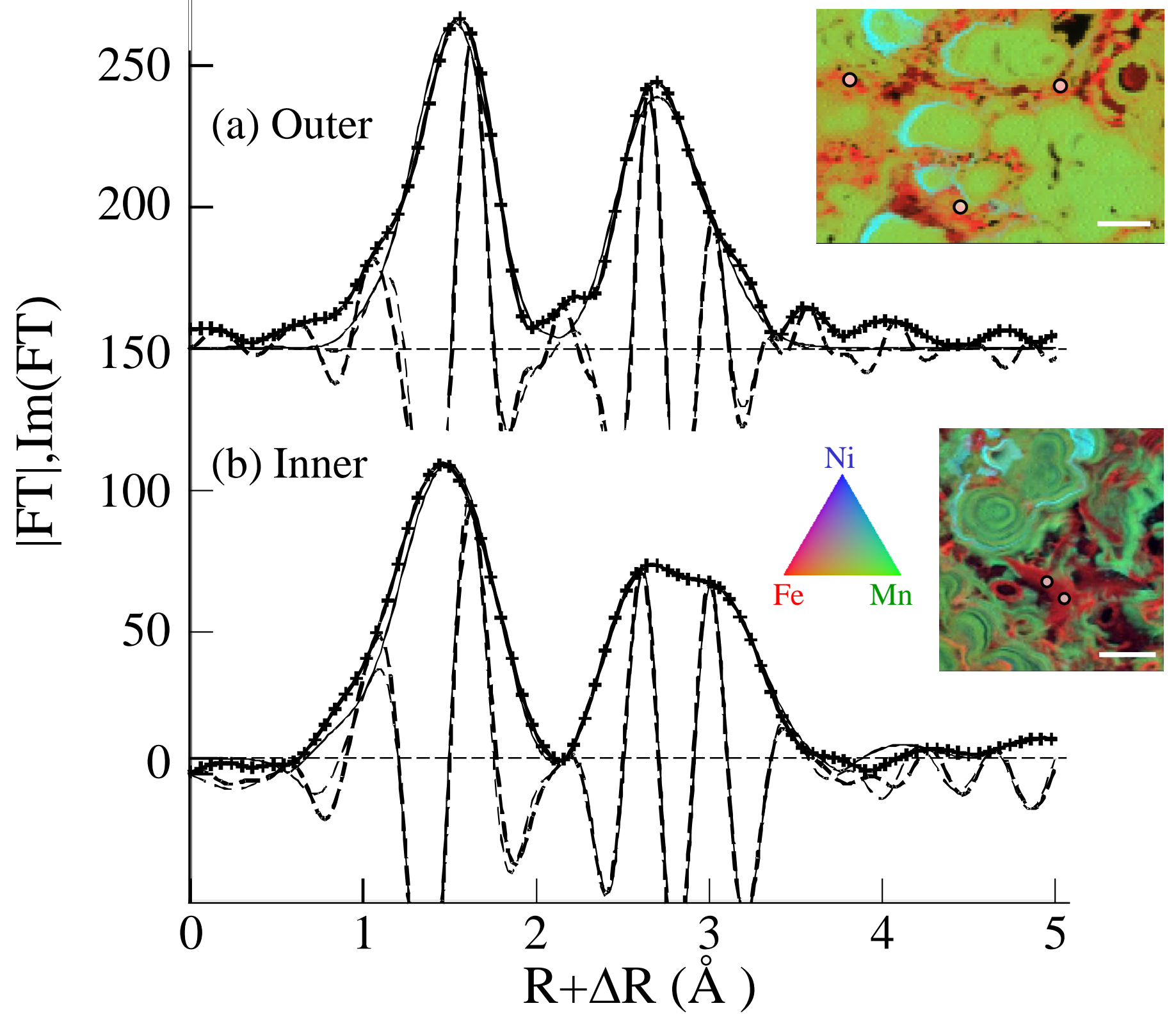




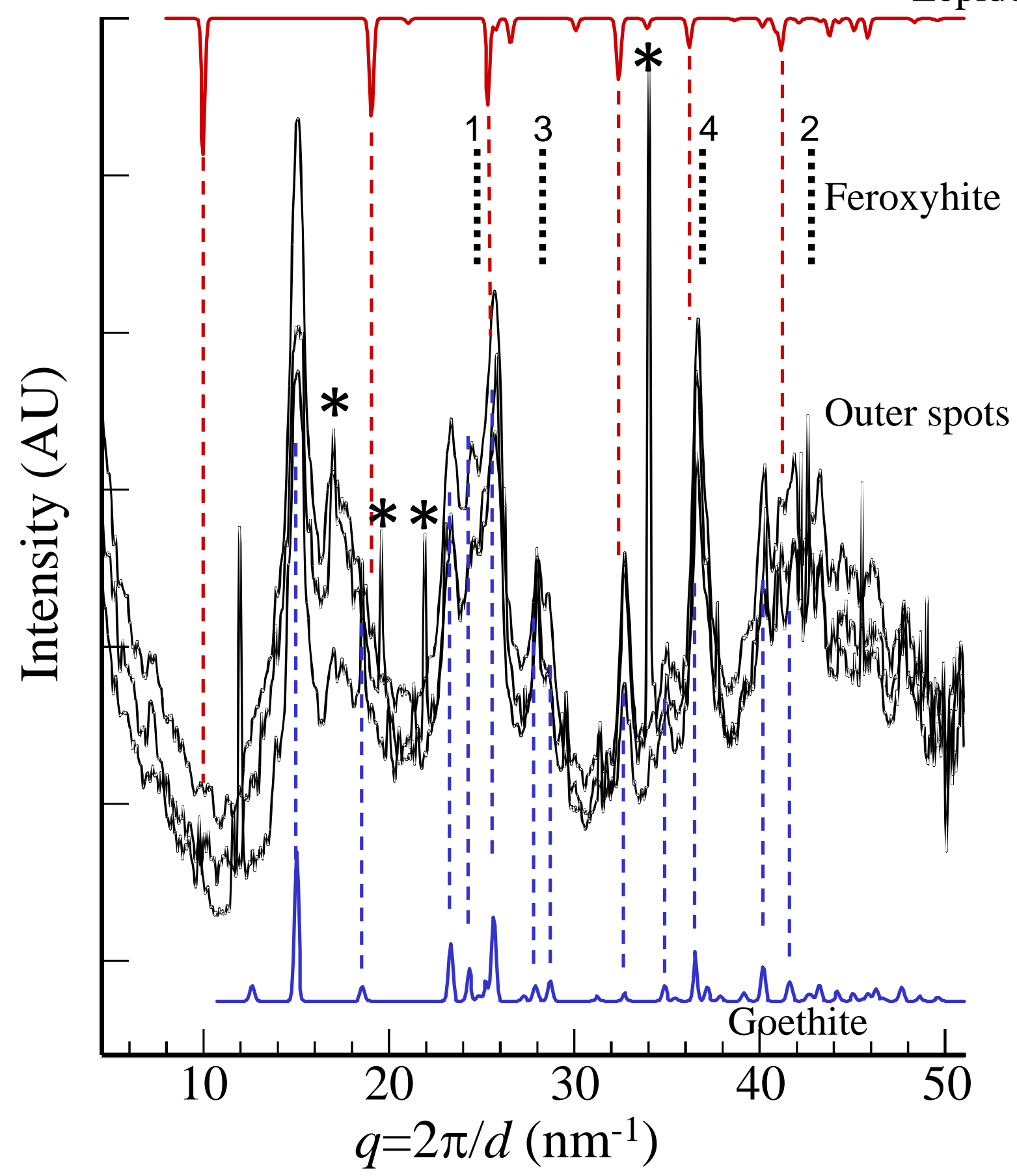




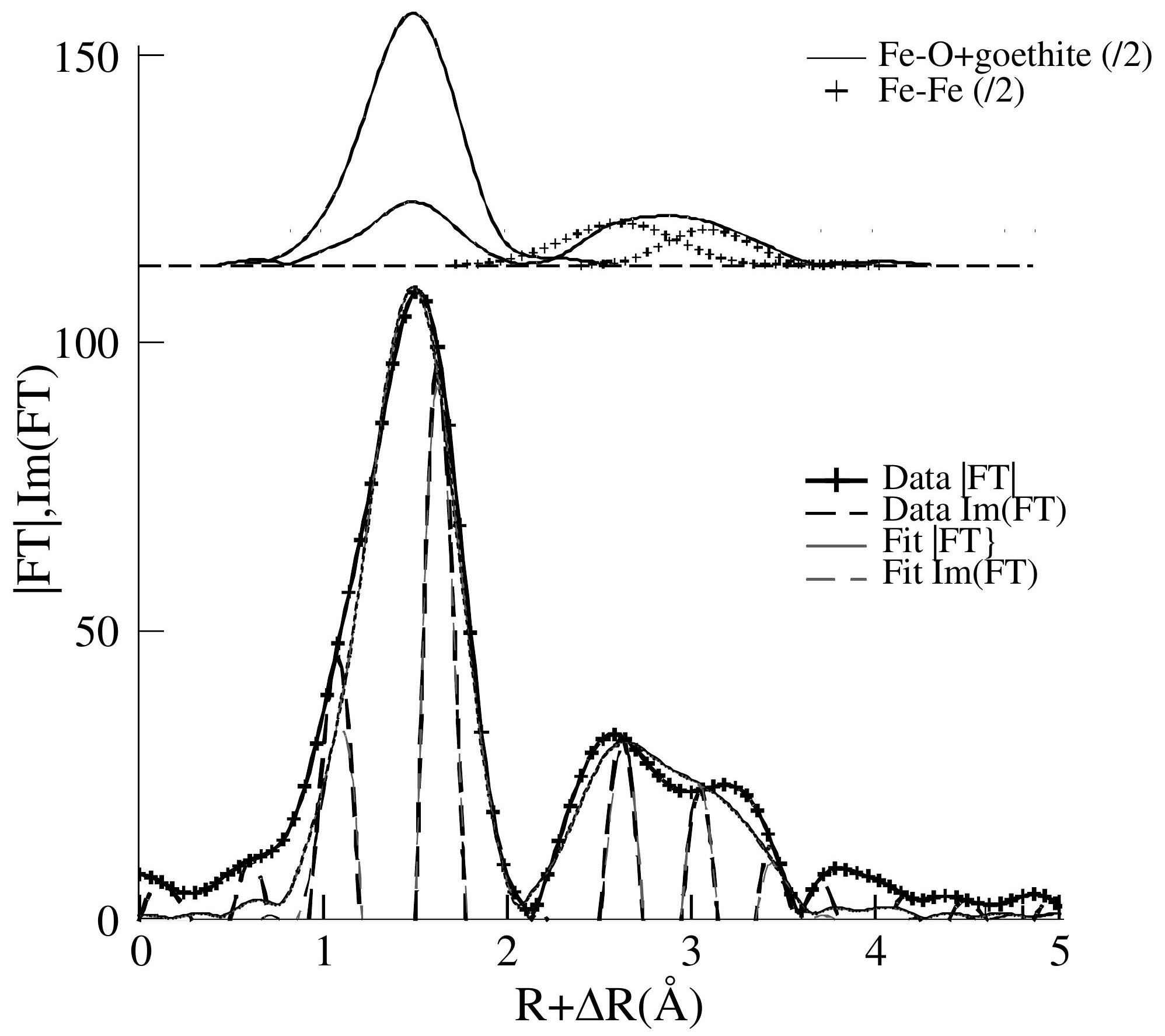




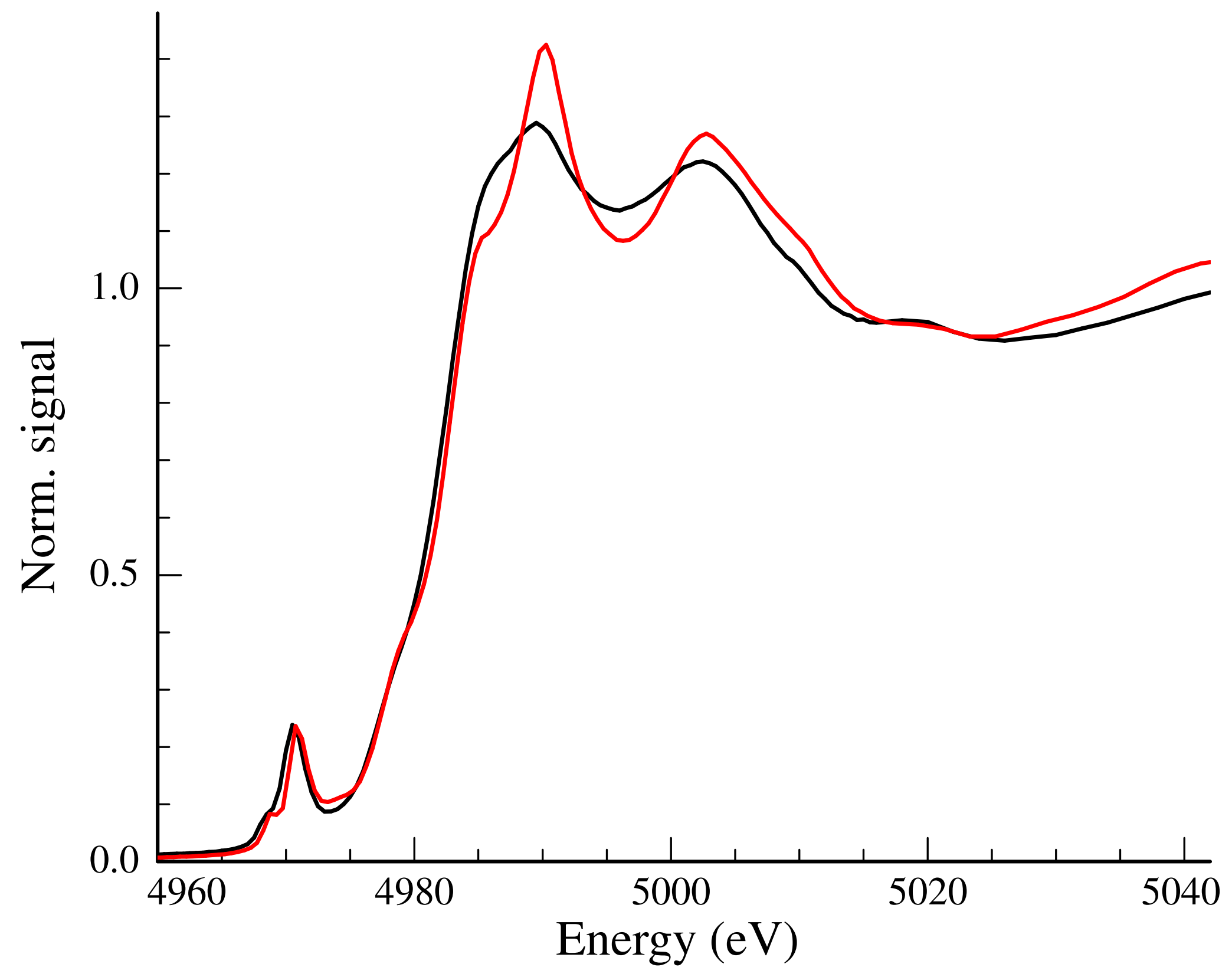




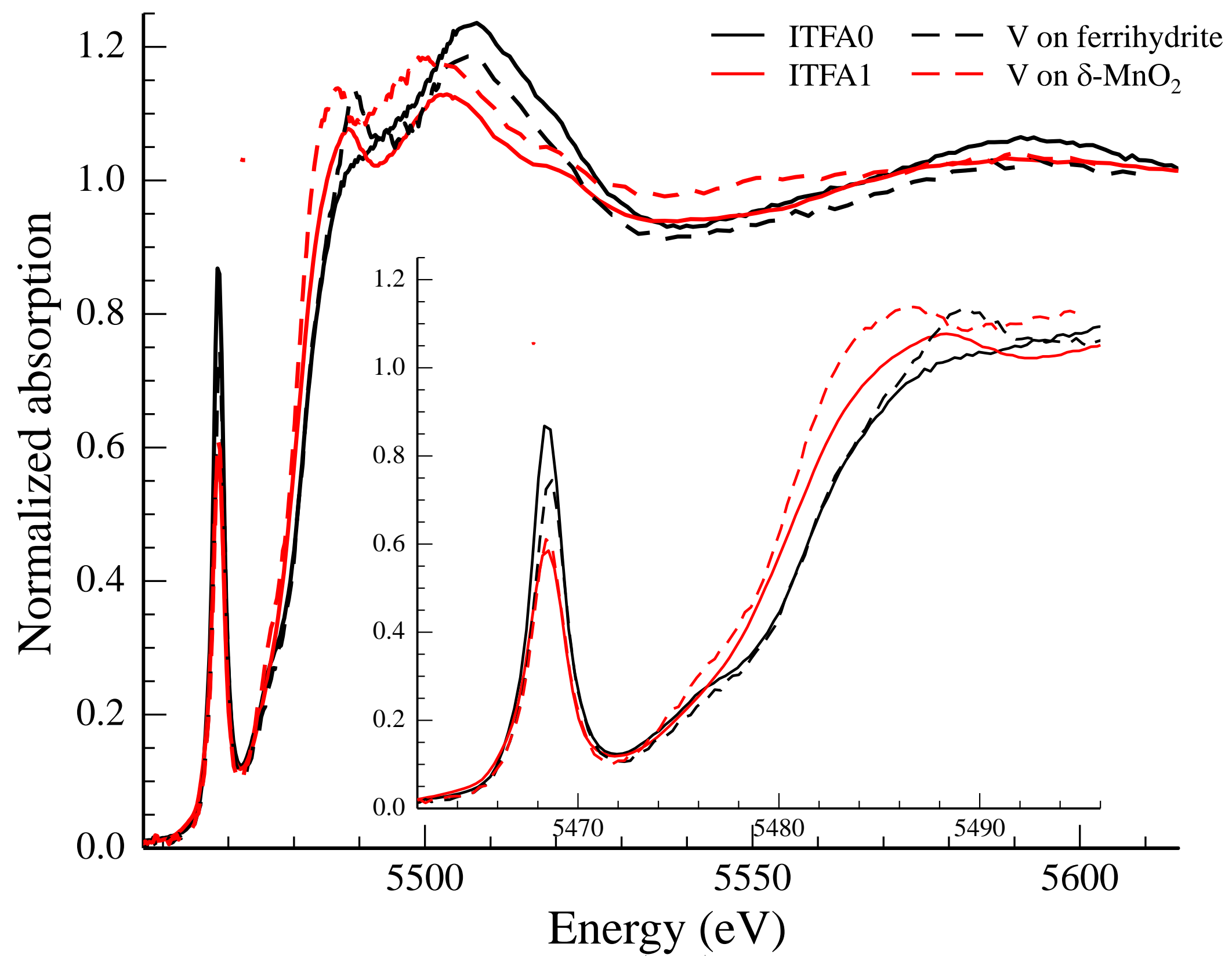




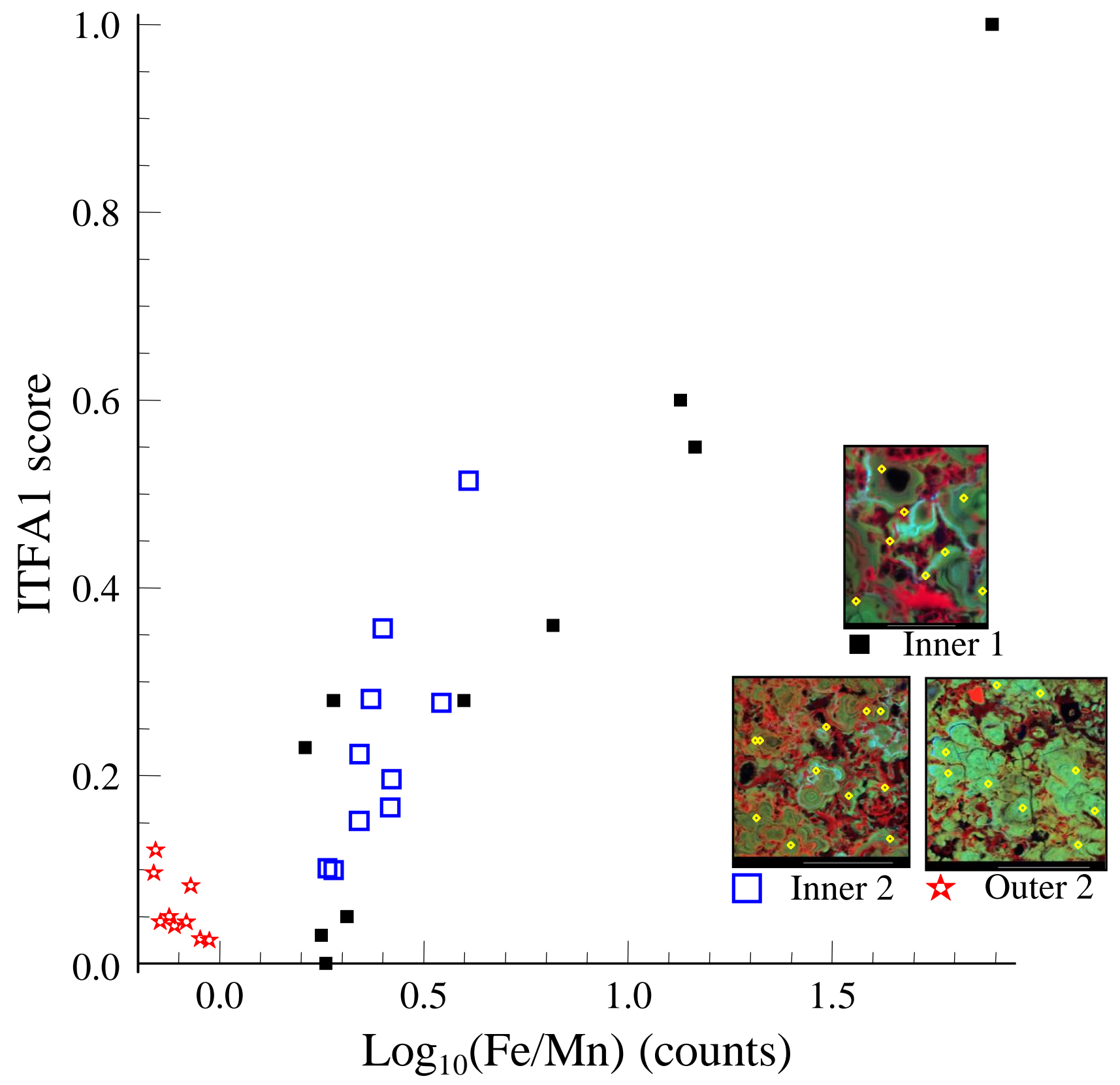




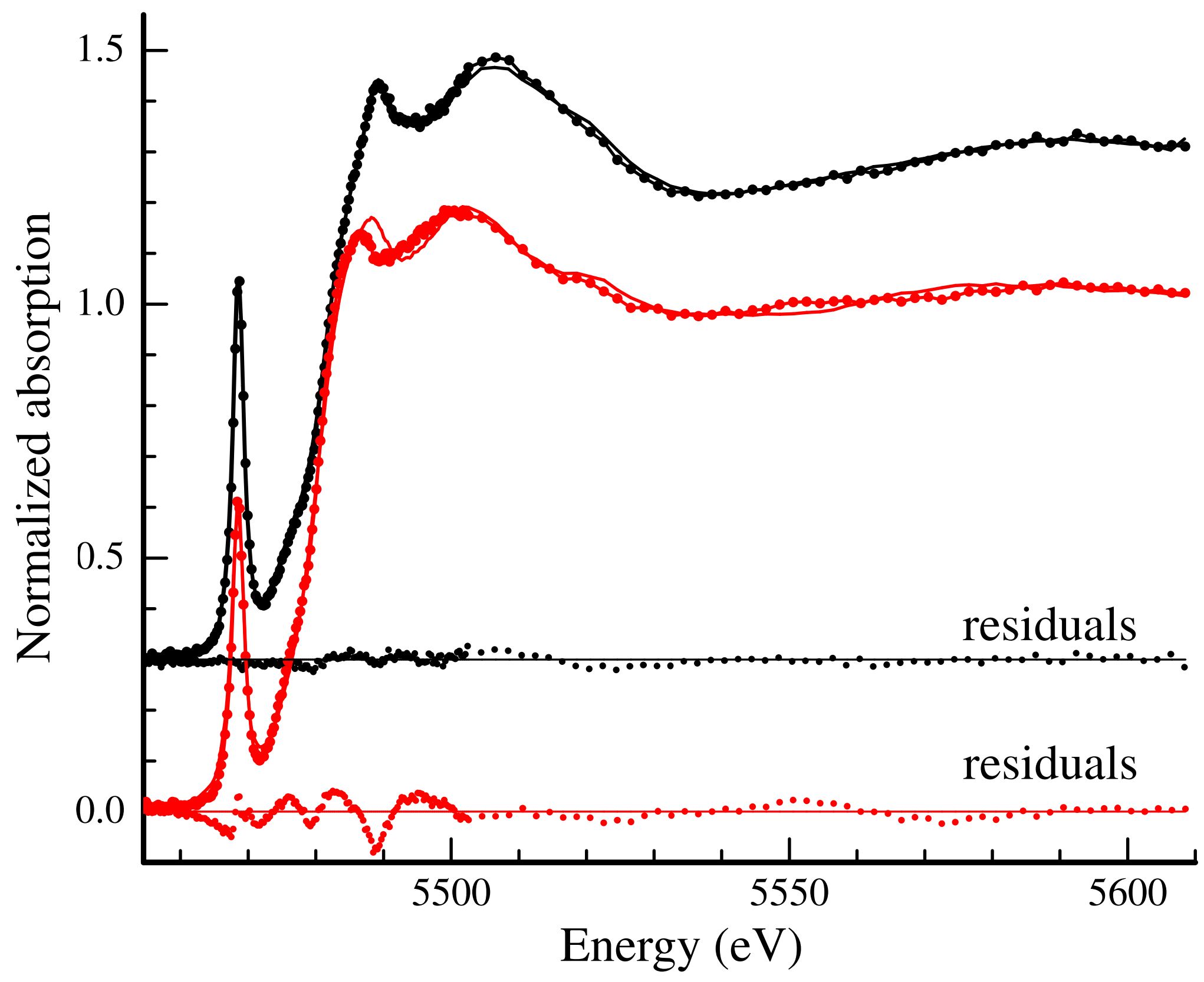

